\title{
Shear layer over floodplain vegetation with a view on bending and streamlining effects
}

\author{
Gerardo Caroppi ${ }^{1}$ (D) · Juha Järvelä ${ }^{1}$ iD
}

Received: 29 October 2021 / Accepted: 30 January 2022 / Published online: 19 February 2022

(c) The Author(s) 2022

\begin{abstract}
Shrubby and woody vegetation growing on floodplains profoundly influences hydrodynamic and transport processes in riverine systems. Existing hydrodynamic research is mostly focused on conditions with aquatic plants and rigid model vegetation. To appreciate the different hydrodynamic impacts of submerged floodplain and riverbank vegetation, a novel flume investigation was carried out. We simulated conditions found in riparian environments in terms of vegetation density, plant structure and flexibility, and presence of a grassy understory. Four experimental cases were defined so that vegetation exhibited different degrees of bending and streamlining. Extensive set of velocity measurements allowed reliable description of the double averaged flow. Vegetation morphology, with the flexibility-induced streamlining and dynamic motion controlled the magnitude and distribution of the vegetative drag, shaping the shear penetration within the canopy. The flows were highly heterogeneous, thus calling for spatially averaged approaches for the flow field investigation. The relative importance of dispersive momentum fluxes was high in the canopy bottom region where both Reynolds and dispersive stresses were small. The contribution of dispersive fluxes to momentum transport decreased with increasing reconfiguration. The results revealed the shear layers over floodplain vegetation to be dynamically similar to other environmental flows over porous obstructions. However, the velocity-dependent vegetative drag and deflected height introduced additional complexity in the flow simulation. Altogether our findings implied that accurate description of vegetated floodplain flows can be achieved only when plant morphology and flexibility are appropriately described in drag models.
\end{abstract}

\section{Article highlights}

- A novel experimental setup with flexible woody plants and grasses was used to model the hydrodynamics of vegetated floodplains.

- Plant morphology and flexibility controlled the vegetative drag, affecting key shear layer features, including the shear penetration.

- The spatially heterogeneous flows had higher dispersive stresses at the canopy bottom, where the total fluid stress was small.

Keywords Shear layer · Floodplain vegetation - Submerged vegetation · Reconfiguration · Turbulence $\cdot$ Flow spatial variability

Extended author information available on the last page of the article 


\section{Abbreviations}

$a$

$A_{B}$

$A_{L}$

Bed area $\left[\mathrm{L}^{2}\right]$

$A_{s}$

One-sided leaf area $\left[\mathrm{L}^{2}\right]$

$A_{L} / A_{S}$

$B$

Frontal stem area [ $\left.\mathrm{L}^{2}\right]$

$C_{D}$

Leaf to stem area ratio [-]

$C_{D} a$

$\left\langle C_{D} a\right\rangle$

$\left\langle C_{D} a\right\rangle_{p}$

$\left\langle C_{D} a\right\rangle_{g}$

$f$

$g$

$h$

$h_{g}$

$h_{p}$

$h_{v}$

$S$

$l$

LAI

$Q$

$r_{x z}$

$R_{\varepsilon}$

$R e_{\theta}$

$S_{x x}$

$u, v, w$

Flume width [L]

Drag coefficient [-]

Drag-density parameter $\left[\mathrm{L}^{-1}\right]$

Local double averaged drag-density parameter $\left[\mathrm{L}^{-1}\right]$

Bulk drag-density parameter of the canopy $\left[\mathrm{L}^{-1}\right]$

Drag-density parameter of the bottom grasses $\left[\mathrm{L}^{-1}\right]$

Frequency $\left[\mathrm{T}^{-1}\right]$

Gravitational acceleration $\left[\mathrm{LT}^{-2}\right]$

Water depth [L]

Bottom grasses height [L]

Penetration depth [L]

Deflected height of vegetation [L]

Flume slope [-]

Mixing length [L]

Leaf area index [-]

Discharge $\left[\mathrm{L}^{3} \mathrm{~T}^{-1}\right]$

Turbulent correlation coefficient of $u^{\prime}$ and $w^{\prime}[-]$

Reconfiguration level of the $i$ test case, $R_{\varepsilon}=1-\left(\left\langle C_{D} a_{p, i}\right\rangle\left\langle\left\langle C_{D} a_{p, R 1}\right\rangle\right)[-]\right.$

Shear layer Reynolds number [-]

Turbulent spectral ordinate of $u^{\prime}\left[\mathrm{L}^{2} \mathrm{~T}^{-1}\right]$

$\bar{u}, \bar{v}, \bar{w}$

Longitudinal, lateral and vertical instantaneous velocity $\left[\mathrm{LT}^{-1}\right]$

$\langle\bar{u}\rangle,\langle\bar{v}\rangle,\langle\bar{w}\rangle$

Time averaged longitudinal, lateral and vertical velocity $\left[\mathrm{LT}^{-1}\right]$

$u^{\prime}, v^{\prime}, w^{\prime}$

Space (double) averaged longitudinal, lateral and vertical velocity [ $\left.\mathrm{LT}^{-1}\right]$

$\tilde{u}, \tilde{v}, \tilde{w}$

Temporal longitudinal, lateral and vertical velocity fluctuation $\left[\mathrm{LT}^{-1}\right]$

$U_{1}, U_{2}$

$U_{b}$

$U_{C}$

$U_{h_{v}}$

$u^{*}$

$x, y, z$

$z_{1}, z_{2}$

$z_{i}$

$z_{U_{C}}$

$\delta$

$\Delta U$

$\theta$

Spatial longitudinal, lateral and vertical velocity fluctuation $\left[\mathrm{LT}^{-1}\right]$

Equilibrium velocity within the vegetation and the upper layer $\left[\mathrm{LT}^{-1}\right]$

Bulk flow velocity $\left[\mathrm{LT}^{-1}\right]$

Shear layer characteristic convection velocity $\left[\mathrm{LT}^{-1}\right]$

Velocity at the canopy top $\left[\mathrm{LT}^{-1}\right]$

Shear velocity $\left[\mathrm{LT}^{-1}\right]$

Flume Cartesian coordinates [L]

Shear layer limiting positions [L]

Position of the inflection point [L]

Vertical position where $\langle\bar{u}\rangle=U_{C}[\mathrm{~L}]$

Shear layer thickness $[\mathrm{L}]$

Shear layer characteristic velocity difference $\left[\mathrm{LT}^{-1}\right]$

Momentum thickness [L]

Fluid kinematic viscosity $\left[\mathrm{L}^{2} \mathrm{~T}^{-1}\right]$

$\xi \quad$ Fractional contribution of dispersive to total fluid stress [-]

$\rho \quad$ Fluid density $\left[\mathrm{ML}^{-3}\right]$

$\tau \quad$ Total fluid stress $\left[\mathrm{FL}^{-2}\right]$ 


\section{Introduction}

Riverbanks and floodplains are populated by shrubby and woody vegetation adapted to highly variable hydrological and hydrodynamic conditions [1, 2] (Fig. 1). Flow and vegetation periodically interact when overbank flows and floods occur. Such flows potentially cause economic and social losses $[3,4]$, and have the capacity to induce geomorphic restructuring of riverine environments [5] and to enhance pollutants remobilization and dispersion [6]. On the other hand, floodplain and riparian vegetation provides valuable ecosystem services, e.g. by trapping nutrients and pollutants [7], reducing scour and erosion [8], regulating light and temperature [9], and providing food and physical habitat [10]. Furthermore, riparian vegetation can provide flood protection by slowing down the flow and increasing storage capacity [11]. The importance of such ecosystem services has led to increased interest in restoring and promoting vegetation by recent water management policies, including the European Union Water Framework Directive [12]. Consequently, riparian vegetation has been in the focus of a wide range of ecosystem based management strategies and nature-based solutions for riverine environments [13-16].

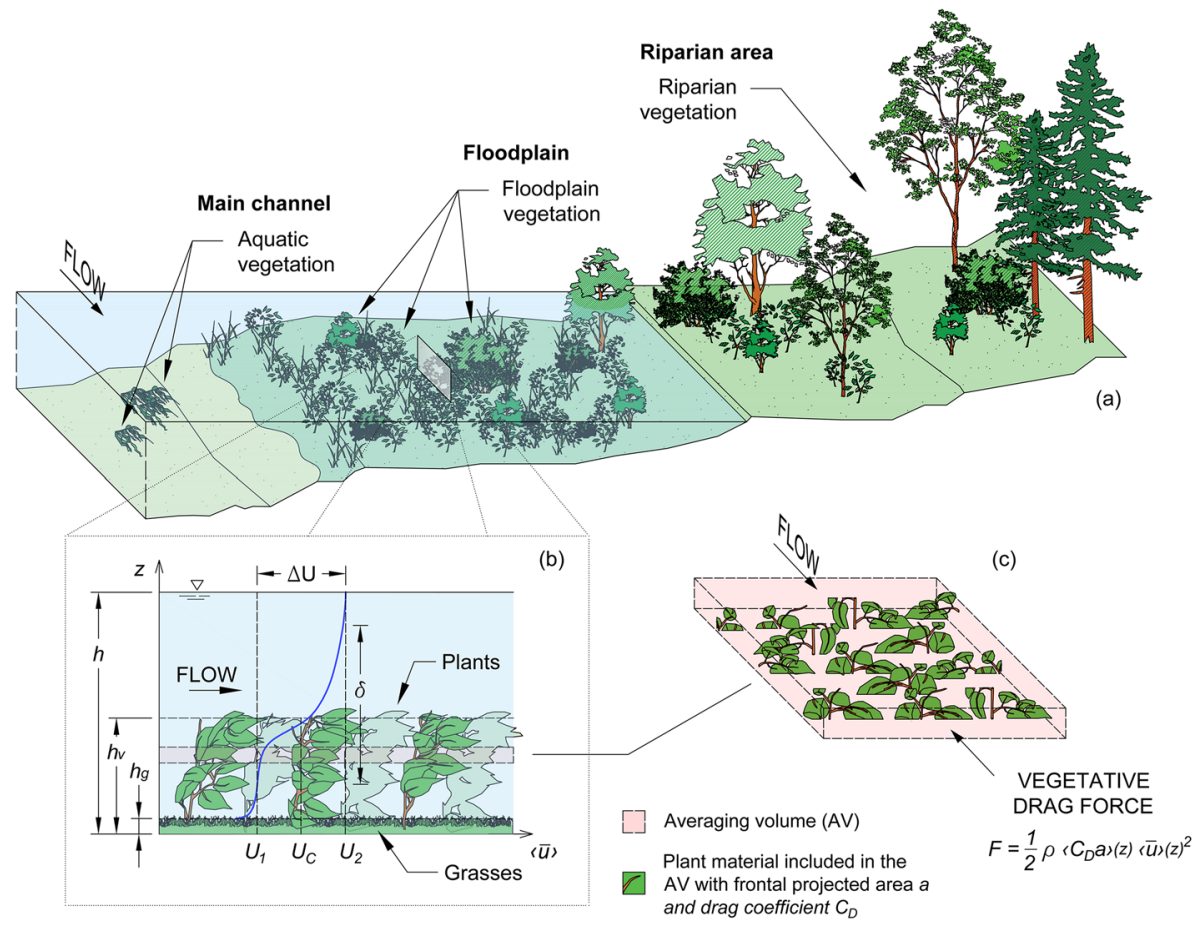

Fig. 1 Schematization of geomorphic and vegetative features of a river section in high-flow condition (a). Flow over submerged floodplain vegetation and vertical velocity profile $\langle\bar{u}\rangle(z)(\mathbf{b})$. Water depth, deflected vegetation height and grasses height are indicated by $h, h_{v}$, and $h_{g}$, respectively. $U_{1}$ and $U_{2}$ are the equilibrium velocities in the canopy and the upper non-vegetated layer, respectively. $U_{C}$ and $\Delta U$ are the shear layer characteristic convection velocity and velocity difference, respectively. $\delta$ is the shear layer thickness (b). Detail of the reference averaging volume for the DAM application (c). Definition of the drag-density parameter $\left\langle C_{D} a\right\rangle$ associated with the drag force $F . \rho$ is the water mass density (c) 


\subsection{Hydrodynamic features of vegetated floodplain flows}

Vegetation greatly impacts hydrodynamic processes at multiple scales [17, 18], influencing flow organization, geomorphic changes, and habitat dynamics [19, 20]. Vegetation introduces additional flow resistance, influencing water-surface elevations and channel conveyance capacity $[21,22]$. By altering the mean and turbulent flow structure, vegetation influences the transport of sediments and substances [23-26]. The key dynamic feature of vegetated flows is the additional drag force exerted by vegetation (Fig. 1) [22, 27]. The drag-density parameter $C_{D} a$ is a convenient measure to characterize flow resistance due to natural plants [28] and was selected for the analyses in this paper. $C_{D} a$ is the product of the vegetative drag coefficient $C_{D}$ and the total plant area $a$, i.e. the frontal projected area of vegetation per unit volume. For a spatially heterogeneous canopy made of flexible plants (Fig. $1 \mathrm{~b}$ and c), $C_{D} a$ should be interpreted as a temporally and spatially averaged value, here indicated as $\left\langle C_{D} a\right\rangle$. Specifically, $\left\langle C_{D} a\right\rangle$ represents the $C_{D} a$ value averaged in time and space over thin plane volumes parallel to the bed, resulting in a vertically variable local drag-density parameter (Fig. 1c). The overall canopy drag can then be described through the canopy bulk drag-density parameter $\left\langle C_{D} a\right\rangle_{p}$, i.e. the $\left\langle C_{D} a\right\rangle$ averaged over the canopy height.

Owing to the drag exerted by plants, the flow velocity deep within the vegetated region is lower than that in the upper non-vegetated area. Consequently, when the flow depth $h$ does not restrict the shear layer growth, strong vertical velocity gradients develop at the interface [29, 30]. The resulting vertical velocity profile, schematically depicted in Fig. 1b, resembles that of a plane mixing layer [31, 32]. In analogy to other environmental flows over porous obstructions [33], the presence of an inflection point makes the flow susceptible to Kelvin-Helmholtz (KH) type instabilities and the onset of large-scale vortices [31, 34, 35]. These vortices dominate the vertical transport of momentum, and by analogy of mass and energy, across the vegetated shear layer [36, 37]. The vortex and the consequent shear penetration within the canopy define the exchange zone, i.e. the region of the canopy rapidly flushed by the vortices that actively exchanges momentum with the upper flow [29, 34]. The extent of the exchange zone is a primary determinant of residence time in the obstruction $[33,38]$ and has been found to scale upon the canopy drag length scale $\left\langle C_{D} a\right\rangle_{p}{ }^{-1}$. The canopy bulk drag $\left\langle C_{D} a\right\rangle_{p}$ is a key dynamic parameter governing the vegetated shear layer [36, 38, 39]. Experiments on flow over submerged canopies revealed the presence of a pronounced inflection point in the velocity profile only for sufficiently dense canopies, i.e. with $\left.\left\langle C_{D} a\right\rangle_{p} h_{v}\right\rangle 0.1$ [35, 38]. Such flow condition is referred to as dense canopy regime. For $\left\langle C_{D} a\right\rangle_{p} h_{v}<0.04$, the velocity profile resembled a boundary layer, with no inflection point, with this regime being referred to as sparse canopy.

The current knowledge of the hydrodynamics of submerged vegetation is mainly based on studies with simplified model vegetation. Conventionally, vegetation has been simulated with a high level of abstraction, reducing canopies of plants of complex structure and bio-mechanical properties into arrays of simple prismatic elements, such as rigid cylinders. While the use of simplified rigid surrogates can be sufficient to reproduce the flow features universally characterizing obstructed shear layers, simplified models do not catch the distinctive features of vegetated flows [33]. These features stem from the complex structure of vegetation, its flexibility and dynamic motion, inducing flow modifications that impact hydrodynamic and transport processes [36, 40-43]. For example, for canopies of tensile aquatic vegetation, differences in turbulent flow 
structure and momentum exchange have been observed in comparison with rigid cylinders $[30,44,45]$. For flows in partly vegetated channels, dynamically similar shear layers induced by rigid cylinders and flexible woody plants presented different extent of the exchange zone and momentum transport efficiency across the vegetated interface [36].

Natural floodplain vegetation typically consists of shrubby an woody plants (Fig. 1a) with different structural properties [46]. In this paper, such vegetation with stems, branches, twigs and leaves is referred to as being morphologically complex. Floodplain vegetation is highly adapted to the stressing hydrodynamic conditions of riparian environments. Owing to their flexibility, plants can adapt to the drag action by progressively streamlining and bending their flexible parts, undergoing a process known as reconfiguration [47, 48]. Because of flexibility, plants exhibit dynamic motions in response to the turbulent flow field. Organized dynamic motion, known as monami, is observed at the top of submerged canopies of flexible aquatic vegetation in response to the passage of large-scale coherent vortices [49-51]. Organized motion of vegetation has been found to alter the vegetative drag and the shear penetration within the canopy [30,52]. Because of reconfiguration and dynamic motion, the spatial distribution of plant material within the canopy varies both in time and space, depending on the mean and turbulent flow. With reference to Fig. 1c, streamlining can alter the posture of plant material contained in the averaging volume, reducing its frontal area and altering its drag coefficient. Plant bending alters the vertical distribution of plant material and the canopy height. Bending and streamlining hinder the determination of the key properties [33], as $\left\langle C_{D} a\right\rangle_{p} h_{v}$, exhibiting large variability due to reconfiguration $[27,53,54]$. Reconfiguration processes are expected to markedly impact the magnitude of $\left\langle C_{D} a\right\rangle$ and its spatial distribution within the canopy, with implications on the hydrodynamic and transport processes occurring in natural systems.

\subsection{Role of spatial variability in flow-vegetation interaction}

The heterogeneous spatial distribution of plant material results in complex spatially variable velocity field. Consequently, the flow has to be analyzed in a spatially averaged sense, adopting a horizontal averaging scheme over a specific spatial scale $[55,56]$. The flow description should be based on a double averaging methodology (DAM) [57], in which flow properties are averaged both in time and space. The application of the DAM to the momentum equation results in an additional stress term represented by the dispersive (or form-induced) stresses, linking the complex subscale flow phenomena to the continuous representation of the flow [58]. Understanding the spatial distribution of canopy flows is essential for developing practical transport models and formulating closure schemes for CFD $[59,60]$. In the presence of flexible vegetation of complex morphology, the investigation of the flow spatial variability is challenging. Canopies of flexible woody plants are optically inaccessible, limiting the use of velocimetry techniques with high spatial resolution, including image velocimetry. The physical accessibility is also restricted, limiting the number of possible measurement positions with intrusive velocimetry techniques, such as acoustic Doppler velocimetry. Creating gaps within the canopy would improve the accessibility of the measuring volume, inevitably jeopardizing the flow spatial variability to be investigated. On the contrary, canopies made of simplified surrogates (rigid cylinders and plates) are easily accessible, allowing high resolution velocity measurements. However, the flow field with rigid vegetation is not expected to be representative of the real conditions, especially for vegetation of more complex hydrodynamic behavior [36, 61]. For example, the relative magnitude of the dispersive stresses was found to be $<5 \%$ of the Reynolds 
stress over the entire canopy height for a dense cylinder array with $\left.\left\langle C_{D} a\right\rangle_{p}\right\rangle 0.8$ [62]. The relative magnitude of dispersive stresses was found to increase with decreasing density, up to $35 \%$ for canopies with $\left\langle C_{D} a\right\rangle_{p} \approx 0.1$, peaking in the canopy bottom layer. Extrapolating these findings to real canopies remains a major challenge not yet undertaken [62]. Indeed, the vegetation representation markedly affects the flow field, affecting the relative importance of dispersive momentum fluxes. Experiments with Salix bushes revealed the contribution of form-induced stresses to be not negligible [63]. For canopies of flexible vegetation of complex morphology, the effect of reconfiguration on the spatially variable flow field and dispersive stresses remains unexplored.

\subsection{Objectives}

The purpose of this paper is to explore the impacts of submerged floodplain vegetation on the flow structure to provide a fluid dynamics-based interpretation of the role of plant morphology and flexibility. The specific objectives were to:

1. Reveal the effects of morphologically complex vegetation and its flexibility-induced reconfiguration on the structure of the vertical shear layer. We expect the structural and morphological properties of floodplain vegetation to govern key shear layer features including the shear penetration. For this purpose, we analyzed the effects of canopy morphology in terms of total plant area per unit volume, plants streamlining and dynamic motion on the drag-density parameter (Sect. 3.1) and presence and position of largescale vortices (Sect. 3.2).

2. Quantify the spatial variability of vegetated floodplain flows and its effects on the momentum transport processes. We anticipate the presence of flexible woody plants to result in increased spatial heterogeneity of flow properties, markedly influenced by reconfiguration. Extensive ADV velocity measurements allowed the analysis of flow spatial variability and its effects on the dispersive momentum fluxes (Sects. 3.3-3.5).

3. Analyze the flows over floodplain vegetation in comparison with other dynamically similar shear layers in order to identify the key hydrodynamic features associated with flexible woody plants (Sect. 3.6). The results revealed the need to account for the reconfiguration-induced vegetative drag variability for improving the hydrodynamic modelling of vegetated flows.

\section{Materials and methods}

\subsection{Experimental arrangement and test cases}

Experiments were carried out at the Environmental Hydraulics Lab of Aalto University in a $20 \mathrm{~m}$ long, $0.6 \mathrm{~m}$ wide and $0.8 \mathrm{~m}$ deep tilting glass-walled recirculating flume. The shear layer in the presence of submerged woody floodplain vegetation was investigated under four bulk flow velocities $U_{b}$ in the range $0.05-0.40 \mathrm{~m} / \mathrm{s}$, resulting in four test cases: R1, R2, $\mathrm{R} 3$ and R4 (Table 1). The bulk flow velocity was evaluated as $U_{b}=Q / B h$, with $Q$ being the discharge, $B$ the flume width, and $h$ the normal water depth. The model canopy was $10.5 \mathrm{~m}$ long and was composed of foliated plants standing on a grassy understory. The vegetation elements were installed on $15 \mathrm{~mm}$ thick polyvinyl chloride (PVC) plates fixed on the flume bed. The $x, y$, and $z$ axes of the flume coordinate system refer to the longitudinal, lateral, 


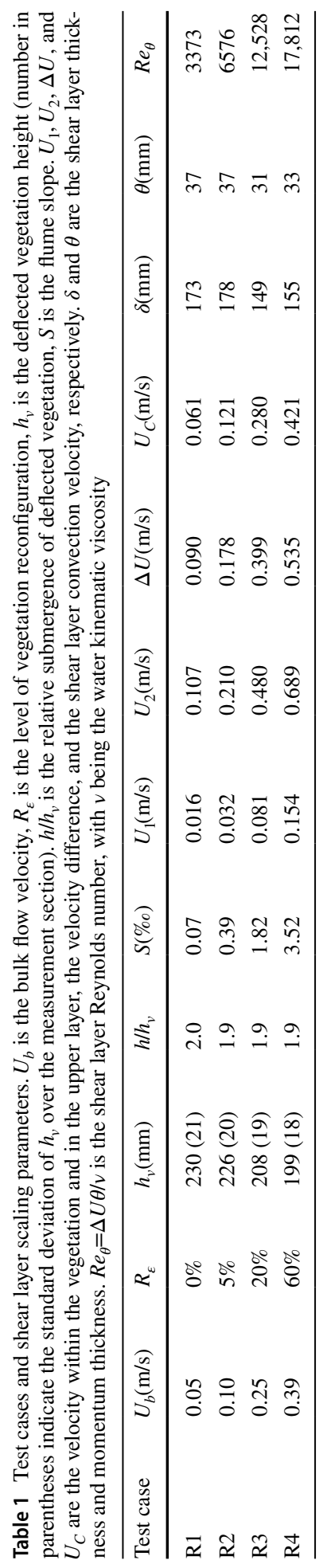


and vertical (normal to the flume bottom) directions, respectively. The coordinate system origin was defined as $x=0$ at the inlet cross-section, positive downstream; $y=0$ at the channel midline and positive toward the left wall (looking downstream); and $z=0$ at the top of the PVC base plate, positive upward. The instantaneous velocity components were denoted as $u, v$, and $w$, in the $x, y$, and $z$ direction, respectively.

The flow was recirculated with a centrifugal pumping system, with discharges ranging from 15 to 90 l/s. The discharge was measured with a magnetic flow-meter (accuracy $0.5 \%$ ). The water depth $h$ was measured with ten pressure sensors (accuracy $\pm 3 \mathrm{~mm}$ ) tapped at the centerline of the flume bed. Discharge and water depth were recorded for $120 \mathrm{~s}$ at $20 \mathrm{~Hz}$ before each test. The flume bed slope and the position of a downstream weir were adjusted to achieve the desired quasi-uniform flow conditions. In all cases, the vegetation submergence ratio $h / h_{v}$ was $\sim 2$, so that the flow depth did not restrict the shear layer development.

\subsection{Model floodplain vegetation: canopy of foliated woody plants with grasses}

The model vegetation consisted of foliated woody plants on a grassy understory. Herein, the term canopy refers to the foliated woody plants. The model vegetation was made of modular plants each composed of a vertical stem (3.8 $\mathrm{mm}$ average diameter) with 4 branches, each with 4 leaves. Two stems of different height (200 and $250 \mathrm{~mm})$ were used to create the two plant types, P1 and P2 depicted in Fig. 2. In the following, the term stem refers to the woody parts of the plants, including the vertical main stem and the branches. The plants were arranged in regular staggered arrays with a longitudinal spacing of $125 \mathrm{~mm}$ and a lateral spacing of 125 and $250 \mathrm{~mm}$ to form a $0.5 \mathrm{~m}$ long repetitive pattern (Fig. 2a, and Figure S1 in the supplementary information (SI)). The spatial arrangement was defined to reproduce natural floodplain conditions and to limit

(a)

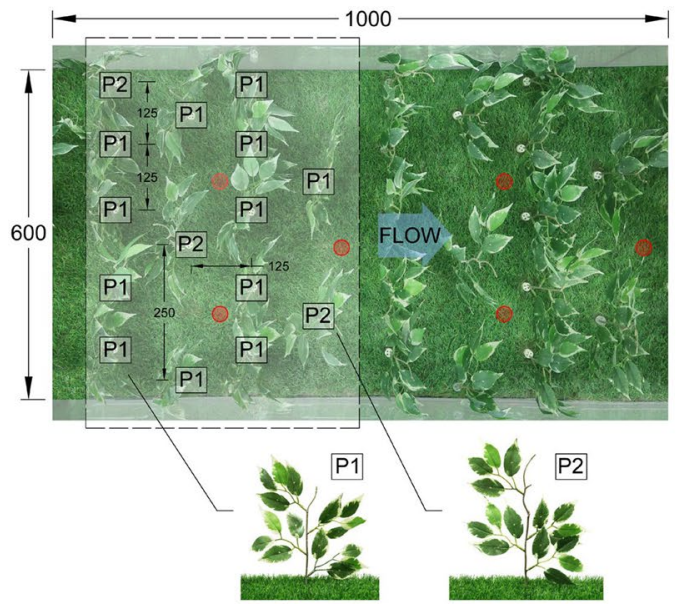

(b)

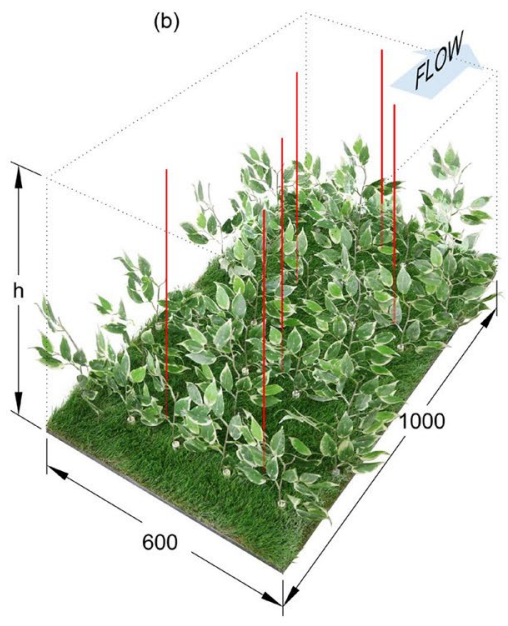

Fig. 2 Top view of the vegetation arrangement with the $0.5 \mathrm{~m}$ long repetitive vegetation pattern indicated by a dashed rectangle (a). The two plants types composing the canopy are indicated as P1 and P2, respectively. Location of the six verticals for the ADV measurements are denoted by the red dots (a) and lines (b). All dimensions are in millimeters 


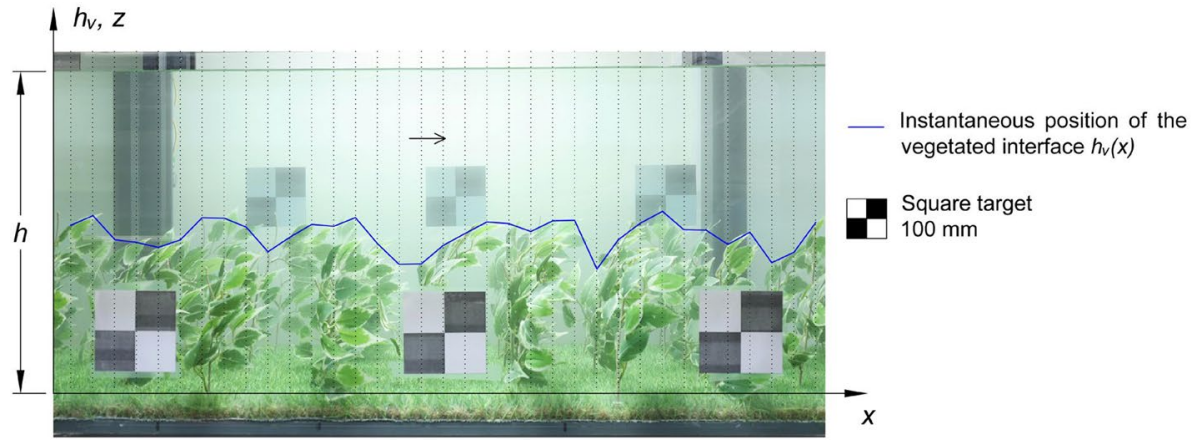

Fig. 3 Side view photo of the $1 \mathrm{~m}$ test section. The vertical dotted lines have a $30 \mathrm{~mm}$ longitudinal spacing, indicating the positions where the height of the plant material was measured. Flow is from left to right

the formation of preferential flow paths within the canopy. The number of plants per $\mathrm{m}^{2}$ of bed area was 50 . The density of the vegetation as expressed by the leaf area index (LAI), defined as the total one-sided leaf area $A_{L}$ of the plants per bed area $A_{B}\left(\mathrm{LAI}=A_{L}\right.$ $\left(A_{B}\right)$, was $\sim 1$, thus in the range of values common for floodplains and lowland rivers in continental and boreal climates [22]. The relation between $A_{L}$ and the frontal stem area $A_{S}$, referred to as the leaf to stem area ratio $A_{L} / A_{S}$, was used for describing the woody foliated vegetation in comparison with common riparian species. The vegetation bulk $A_{L} / A_{S}$, evaluated in dry conditions using image analysis, was equal to 36 , thus in the range of values observed for seedlings of common deciduous riparian species, including Populus and Salix [54]. The plants showed reconfiguration behavior similar to that of natural floodplain plants [36], as observed from the drag force measurements carried on isolated plants (Figure S5, SI). The vertical distribution of the canopy frontal area per unit volume $a(z)$ (Figure S4, SI) was evaluated in dry conditions from photos of P1 and P2 plants, for which the measurements from three different plants (both for P1 and P2) were averaged. The grassy bed roughness was introduced to improve the representativeness of natural conditions where low grasses typically grow beneath shrubs and trees $[64,65]$. The bottom grasses remained fairly erect with height $h_{g}$ of $\sim 40 \mathrm{~mm}$. The frontal area of grasses per unit volume was $\sim 120 \mathrm{~m}^{-1}$. Additional details on the model canopy and the experimental facility are included in the SI.

The definition of the vegetation height is crucial in the analysis of vegetated shear layers [66]. In hydraulic analyses the use of deflected plant height is required for the appropriate description of the flow conditions [67, 68]. Consequently, $h_{v}$ was defined as the height of plant material (stems, leaves, twigs) above the flume bed and evaluated in analogy to the point-plot method, a technique for manually surveying vegetation height in the field [69]. The method was adapted to account for the dynamic motions of plants. Videos taken during the experiments from the flume side were used to evaluate the temporally and spatially averaged value of $h_{v}$. For each test case $16-20$ frames at $0.5-3 \mathrm{~Hz}$ were extracted from the videos. The vegetation height over the $1 \mathrm{~m}$ test section was measured for each frame with a $30 \mathrm{~mm}$ spacing, resulting in $h_{v}(x)$, the instantaneous position of the vegetated interface (Fig. 3). The 16-20 instantaneous interface positions were averaged in time, obtaining $\overline{h_{v}}(x)$, the temporally averaged position of the vegetated interface. $\overline{h_{v}}(x)$ was then averaged over the test section to obtain the double averaged value of the deflected canopy height $h_{v} \equiv\left\langle\overline{h_{v}}\right\rangle$. The vegetation height in still water 
was calculated from 2 photos and was equal to $229 \pm 26 \mathrm{~mm}$ (with SD indicating the spatial variability over the test section). $h_{v}$ of the four test cases are indicated in Table 1. The videos of the tests are available in the SI.

\subsection{Reconfiguration and dynamic motion of plants}

The position of two selected plants was tracked to quantify the plant motions. Specifically, the tip of the uppermost leaf of one P1 and one P2 plant in the central region of the flume was tracked for $60 \mathrm{~s}$ at 10 and $15 \mathrm{~Hz}$ for R1 and R2, respectively, and for $30 \mathrm{~s}$ at $30 \mathrm{~Hz}$ for R3 and R4. From R1 to R4, the increasing $U_{b}$ resulted in increasing plant bending and streamlining, as shown in Fig. 4. For cases R3 and R4, with the highest $U_{b}$, the plants showed marked organized dynamic motion (videos, SI).

For R1 case, the plants remained erect showing only little, low frequency motion (videos, SI). Reconfiguration and dynamic motion effects were considered to be negligible for this case. Consequently, the bulk drag-density parameter of R1 case $\left(\left\langle C_{D} a\right\rangle_{p, R 1}\right)$ was assumed to be representative of non-reconfigured vegetation and used to quantify the relative level of reconfiguration $R_{\varepsilon}$ of the R2-R4 cases. $R_{\varepsilon}$ of the $i$ test case was evaluated as :

$$
R_{\varepsilon}=1-\frac{\left\langle C_{D} a\right\rangle_{p, i}}{\left\langle C_{D} a\right\rangle_{p, R 1}} .
$$

The increasing streamlining of plants (Fig. 4) resulted in $R_{\varepsilon}$ of 5, 20 and $60 \%$ for R2, $\mathrm{R} 3$ and R4, respectively (Table 1). The vertical distribution of $a(z)$ evaluated in dry conditions was assumed to be representative of the vertical distribution of the frontal area of the canopy for the R1 test case, i.e. for non-reconfigured conditions.

The plant motion (videos, SI) was investigated through the spectral analysis of the time series of the tracked points. The frequency and the amplitude of plant motions increased from R1 to R4. The average amplitude of plant vertical motion at the interface was 9, 26, 59 and $64 \mathrm{~mm}$, for R1-R4, respectively. The dominant frequency of motion of the two tracked plant subparts is reported in Table 3. The plant subparts exhibited different types of motion, being more pronounced for cases R3-R4 with the highest $U_{b}$ (e.g. flapping of leaves, bending and oscillation of main stems). The motion of plants at the same $x$ position was not synchronous, indicating the presence of different "monami channels", in consistence with observations on aquatic and terrestrial canopies $[31,70]$.

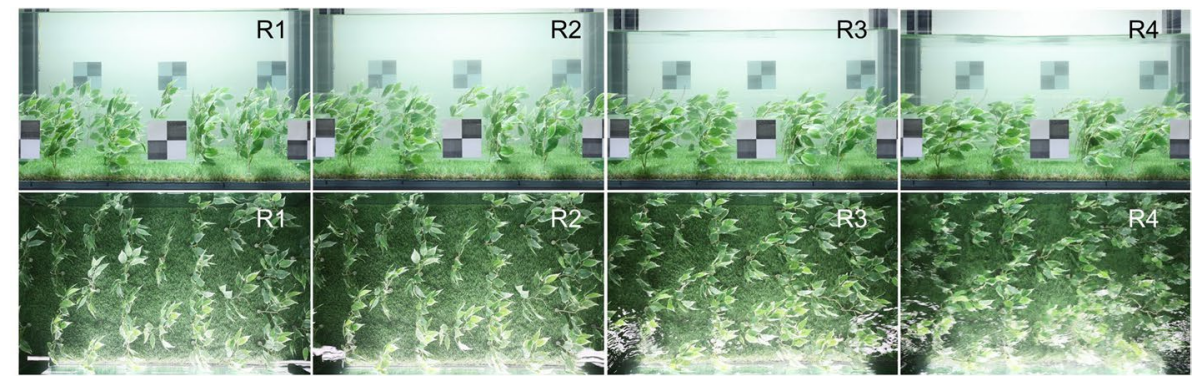

Fig. 4 Pictures from the flume side (top row) and top (bottom row) showing the increasing plant bending and streamlining from R1 to R4. Flow is from left to right. Plant motions are documented in the SI videos 


\subsection{ADV measurement of flow field and double averaging procedure}

The flow field measurement was carried out with acoustic Doppler velocimetry in the $1 \mathrm{~m}$ long test section located $8 \mathrm{~m}$ downstream from the leading edge of the vegetated reach. Velocity measurements over the $10.5 \mathrm{~m}$ long vegetated reach indicated that the flow entering the test section was fully developed and the shear layer reached an equilibrium condition [71]. For each test, six vertical velocity profiles were measured with an acoustic Doppler velocimeter (ADV) Nortek Vectrino+ with a 4-beam down-looking probe (accuracy $\pm 1 \%$ ). The six verticals were distributed in the $300 \mathrm{~mm}$ wide section around the centerline of the flume (Fig. 2) to minimize the impact on the measurements of possible secondary currents in the flow in the upper non-vegetated layer. At each point, velocity was measured at $200 \mathrm{~Hz}$ for $120 \mathrm{~s}$. The flow was seeded with solid glass micro-spheres (average particles diameter of 7-10 $\mu \mathrm{m}$ ) to achieve good ADV operational conditions for the entire duration of the measurements. Each vertical profile consisted of 38-32 measurement points with a spacing of 5-10 $\mathrm{mm}$, with $5 \mathrm{~mm}$ used for the three points closest to the top of the bottom grasses. The vertical profiles extended up to the $86 \%$ of the water depth since the uppermost $50-60 \mathrm{~mm}$ could not be sampled by the ADV. The ADV raw data were processed by filtering out the values with signal-to-noise ratio and correlation lower than $15 \mathrm{~dB}$ and $70 \%$, respectively, and despiked with the modified phase-space thresholding method [72, 73], as in Caroppi et al. [74, 75].

The spatial sampling of the flow was restricted to few strategical locations within the canopy because of both instrumentation requirements and practical limitations. The number of verticals and their spatial location in the test section were defined to reliably describe the spatially and temporally averaged flow. Each vertical was placed approximately at the farthest location from the closest plants to be fully accessible by the probe without the need to create gaps in the vegetation, i.e. without altering the flow field. Placing the measurement positions away from surrounding obstacles (e.g. farthest locations from plants) can reduce the deviations from the double-averaged flow in comparison with other locations inside the canopy [60].

To describe the spatially heterogeneous flow over submerged floodplain vegetation, the DAM $[57,76,77]$ was adopted. The time-averaged flow features were spatially averaged in planes parallel to the bed. The generic instantaneous variable $\theta$ was decomposed into a time averaged part, denoted by an overbar, and a temporally fluctuating part, denoted by a prime, according to $\theta=\bar{\theta}+\theta^{\prime}$. Analogously, the time-averaged variable $\bar{\theta}$ was decomposed into a spatially-averaged part $\langle\bar{\theta}\rangle$, denoted by square brackets, and a spatially fluctuating part $\tilde{\theta}$, denoted by a tilde, according to $\bar{\theta}=\langle\bar{\theta}\rangle+\theta$. The generic double-averaged property $\langle\bar{\theta}\rangle$ was calculated at each measurement height by averaging the $\bar{\theta}$ available at that height. $\langle\bar{\theta}\rangle$ was assumed to represent the whole measurement volume at that height.

Spatial averaging was performed over volumes ideally represented by thin slabs parallel to the flume bed of thickness equal to the height of the ADV sampling volume $(7 \mathrm{~mm})$. The plan area of the averaging volume was assumed to coincide with the area covered by the ADV measurements, i.e. $\sim 1 \mathrm{~m}$ long and $\sim 0.4 \mathrm{~m}$ wide in the central region of the flume, thus larger than the vegetation height and the spacing between plants [57]. At each elevation, six points were sampled without altering the plant material distribution (Fig. 2). The points were located approximately at the farthest location from surrounding plant material as to increase the representativeness of the measurements of the double-averaged flow [60]. For a canopy of plants of complex morphology, flow spatial 
variability occurs at different scales [17]. In the present experiments, spatial variability occurred at the scale of plants sub-parts (leaves, stems), at the scale of spacing between plants, and at the scale of the vegetation pattern (Fig. 2). The measurement strategy was considered adequate to account for the sub-scale flow phenomena occurring at the scale of the vegetation pattern.

The ADV measurements and the DAM were used to describe the double averaged flow, the flow spatial variability and the dispersive stresses. It should be noted that calculation of dispersive stresses requires detailed spatial information about the flow, with flow spatial subsampling affecting the reliability of the dispersive stresses magnitude assessment [78]. Nevertheless, point-based measurements can be used to provide reliable description of the vertical distribution of dispersive stresses [51]. The measurement strategy adopted herein is a tradeoff between the representativeness of flow features of natural conditions and the number of possible measurement points. The use of complex morphology vegetation (Fig. 2) while carrying velocity measurements without removing any plant parts ensured a realistic representation of natural floodplain flow conditions. Moreover, carrying measurements avoiding plant parts to enter the ADV acoustic beams and sampling volume resulted in reliable velocity measurements. At the same time, the use of morphologically complex vegetation resulted in a physically less accessible canopy, limiting the number of possible measurement positions. Consequently, the results on dispersive stresses refer to the accessible measurement locations of Fig. 2 and, thus, need to be treated with caution. To tackle the limitations, the description of the dispersive stresses in the following is focused on their vertical distribution, with their magnitude discussed in a comparative way between cases R1-R4. The uncertainty in assessing the magnitude of the dispersive stresses was justified considering the new knowledge gained. Measurements of flow spatial variability in the presence of submerged flexible woody floodplain vegetation have not been reported in literature. Previous investigations are limited to flows with rigid surrogates [58, 62, 78-80].

\subsection{Properties and metrics describing the flow}

The flow description is based on double averaged normalized flow properties. Characteristic lengths and velocities as defined for plane mixing layers and evaluated from the double averaged velocity profile $\langle\bar{u}\rangle$ were used as scaling quantities (Table 1 ). The shear layer characteristic velocity difference $\Delta U=U_{2}-U_{1}$ and convection velocity $U_{c}=\left(U_{1}+U_{2}\right) / 2$ were used as scaling velocities. For all the tests, the velocity reached an approximately constant value in the uppermost region (from $z / h_{v}>1.6-1.7$ ), and subsequently, $U_{2}$ was evaluated as the average velocity in this region. Within the vegetation, the velocity reached an approximately constant value only for test cases R1-R3. Since the shear at the interface was the key feature of all the test cases, $U_{1}$ was evaluated based on the vertical distributions of Reynolds stresses, by averaging the velocity in the lowermost region of the canopy not penetrated by shear. The shear layer thickness $\delta$ was defined as the cross flow distance between vertical positions $z_{1}$ and $z_{2}$, where velocity reached the values $U_{1}+0.1 \Delta U$ and $U_{2}-0.1 \Delta U$, respectively [81]. The momentum thickness $\theta$ was evaluated as [82]:

$$
\theta=\int_{-\infty}^{+\infty}\left\{0.25-\left[\left(\langle\bar{u}\rangle-U_{c}\right) / \Delta U\right]^{2}\right\} d z
$$

The shear layer thickness $\delta$ and the momentum thickness $\theta$ were used as scaling lengths. The vertical coordinate $z$ was made dimensionless with the deflected vegetation height. In 
comparable studies, the friction velocity $u^{*}$, defined as the square root of $-\left\langle\overline{u^{\prime} w^{\prime}}\right\rangle_{\max }$, is generally used as scaling velocity $[68,83]$. From a hydrodynamic viewpoint $\Delta U$ and $u^{*}$ are equivalent quantities both describing the flow total shear, as confirmed by their ratio $\Delta U$ $/ u^{*}=6.6 \pm 0.1$ for our tests.

The effects of reconfiguration and dynamic motions on the vegetative drag were investigated by analyzing the vertical distributions of the drag-density parameter $\left\langle C_{D} a\right\rangle$, as evaluated from the double averaged momentum equation. For a submerged canopy, the momentum equation reads as $[29,55]$ :

$$
-\rho g \frac{d h}{d x}+\frac{\partial \tau}{\partial z}-\frac{1}{2} \rho\left\langle C_{D} a\right\rangle\langle\bar{u}\rangle^{2}=0
$$

where $\rho$ is the fluid mass density and $g$ is the gravitational acceleration. In uniform flow conditions, $d h / d x=-S$. The total fluid stress $\tau$ is composed of Reynolds and dispersive stresses as [50]:

$$
\tau=\rho\left(-\left\langle\overline{u^{\prime} w^{\prime}}\right\rangle-\langle\tilde{u} \tilde{w}\rangle\right)
$$

For flows over permeable media, the double-averaged momentum equation should account for the share of the volume occupied by water relative to the total averaging volume through the introduction of a roughness density function $\phi(z)$ [55, 84]. In Eq. (1), the roughness density function was omitted. The model canopy (Fig. 2) had a bulk solid volume fraction of $\sim 0.14 \%$, corresponding to a bulk roughness density $\sim 1$. However, it should be noted that for the used vegetation, the bulk $\phi$ value may not be representative of the actual local conditions, being also velocity-dependent. In Eq. (1), the contribution of viscous stress was neglected. For $z=40 \mathrm{~mm}$, assuming $\tau=0$ at the flume bed, Eq. (1) was used to estimate the drag exerted by the bottom layer, including the contribution of the grasses and the first $40 \mathrm{~mm}$ of plant stems. In this layer, the frontal stem area per unit volume was $0.0076 \mathrm{~m}^{-1}$, being negligible in comparison to the contribution of the grasses $(a$ $\approx 120 \mathrm{~m}^{-1}$ ). Consequently, $\left\langle C_{D} a\right\rangle$ at $z=40 \mathrm{~mm}$ was denoted as $\left\langle C_{D} a\right\rangle_{g}$ and used to describe the drag of the bottom grasses. In the calculation of $\left\langle C_{D} a\right\rangle$ from Eq. (1), profiles of $\partial \tau / \partial z$ were smoothed using a $30 \mathrm{~mm}$ moving average. The canopy bulk drag-density parameter $\left\langle C_{D} a\right\rangle_{p}$ was evaluated by averaging $\left\langle C_{D} a\right\rangle$ in the region $\sim 0.2<z / h_{v} \leq 1$.

The effects of reconfiguration-induced drag reduction on the shear layer were investigated by analyzing the vertical distributions of double averaged mean velocity $\langle\bar{u}\rangle$ and Reynolds stress $-\left\langle\overline{\left\langle u^{\prime} w^{\prime}\right.}\right\rangle$. The shape of the velocity profiles was discussed in analogy to canonical mixing layers for which the velocity distribution is conventionally described by the hyperbolic tangent function $[31,85]$ :

$$
\langle\bar{u}\rangle=U_{C}+0.5 \Delta U \tanh \left(\frac{z-z_{U_{C}}}{2 \theta}\right)
$$

where $z_{U_{C}}$ is defined so that $\langle\bar{u}\rangle\left(z_{U_{C}}\right)=U_{C}$ (Table 1 ). The presence of large-scale coherent structures was detected through the spectral analysis of the turbulent fluctuating velocity field. The Welch's method [86] was used to calculate the power spectral density $S_{i i}$ of the fluctuating velocity in the $i$ direction. The efficiency of the momentum transport by Reynolds stress was estimated using the turbulent correlation coefficient $\left\langle r_{x z}\right\rangle$, with $r_{x z}=-\overline{u^{\prime} w^{\prime}}$ $/\left({\overline{u^{\prime 2}}}^{1 / 2}{\overline{w^{\prime 2}}}^{1 / 2}\right)$ [87]. The extent of the region where $\left\langle r_{x z}\right\rangle>0.32$, i.e. the maximum value observed for boundary layers $[31,87]$, was used to provide information on $\delta_{v}$, the vertical 
extent of large-scale vortices. The extent of the exchange zone $h_{p}$, i.e. the extent of the region within the canopy penetrated by the shear, was evaluated from the Reynolds stress profile. $h_{p}$ was evaluated as the distance between the vegetated interface and the position within the canopy where $-\left\langle\overline{u^{\prime} w^{\prime}}\right\rangle$ decayed to $10 \%$ of its maximum value $[34,88]$. The turbulent flow structure was described by the double averaged vertical distributions of turbulence intensities $\left\langle\overline{u^{\prime 2}}\right\rangle^{1 / 2},\left\langle\overline{v^{\prime 2}}\right\rangle^{1 / 2}$ and $\left\langle\overline{w^{\prime 2}}\right\rangle^{1 / 2}$. The quantity $0.5\left(\left\langle\overline{u^{\prime 2}}\right\rangle+\left\langle\overline{v^{\prime 2}}\right\rangle+\left\langle\overline{w^{\prime 2}}\right\rangle\right)$ represents the turbulent kinetic energy.

The flow spatial variability was analyzed through the vertical distributions of $\left\langle\tilde{u}^{2}\right\rangle^{1 / 2}$, $\left\langle\tilde{v}^{2}\right\rangle^{1 / 2}$ and $\left\langle\tilde{w}^{2}\right\rangle^{1 / 2}$, indicated as form-induced intensities. Each quantity is the standard deviation of the corresponding spatially averaged velocity at that measurement height, providing information on the spatial variability of time averaged velocity among the investigated verticals. $\left\langle\tilde{u}^{2}\right\rangle,\left\langle\tilde{v}^{2}\right\rangle$ and $\left\langle\tilde{w}^{2}\right\rangle$ represent the normal dispersive stresses in the $x, y$ and $z$ direction. The quantity $0.5\left(\left\langle\tilde{u}^{2}\right\rangle+\left\langle\tilde{v}^{2}\right\rangle+\left\langle\tilde{w}^{2}\right\rangle\right)$ is the dispersive kinetic energy [78]. The role of flow spatial variability on the vertical exchange of streamwise momentum was described through the analysis of the vertical distributions of the dispersive shear stresses $-\langle\tilde{u} \tilde{w}\rangle$. The relative importance of dispersive stresses in the total vertical flux of momentum was denoted as $\xi=-\langle\tilde{u} \tilde{w}\rangle / \tau$, evaluated as the ratio of the dispersive to total fluid stress.

The features of the vegetated floodplain flows were discussed in comparison to other environmental obstructed shear layers. For obstructions with $\left\langle C_{D} a\right\rangle_{p} h_{v}>0.25$ and $\left\langle C_{D} a\right\rangle_{p}\left(h_{v}\right.$ $-h)>0.5$, shear layers have been found to share the following four scaling relations independently from the nature of the obstruction [33]:

$$
\begin{gathered}
\frac{\overline{\left\langle w^{\prime 2}\right\rangle^{1 / 2}}}{\overline{u^{*}}} \approx 1.1 \\
\frac{\left.\overline{\left\langle w^{\prime 2}\right.}\right\rangle}{\left.\overline{\left\langle u^{\prime 2}\right.}\right\rangle} \approx 0.6 \\
\left\langle C_{D} a\right\rangle_{p} h_{p} \approx \frac{1}{3} \\
\frac{U_{h_{v}}-U_{1}}{u^{*}} \approx 2.6
\end{gathered}
$$

In these scaling relations $\left\langle\overline{u^{\prime 2}}\right\rangle$ and $\left\langle\overline{w^{\prime 2}}\right\rangle$ are the root mean square levels of the longitudinal and vertical fluctuating velocities at the interface $\left(z / h_{v}=1\right), U_{h_{v}}$ is the velocity at the canopy top. Equations (4-7) were used to investigate the dynamic similarity between the shear layers over floodplain vegetation and other analogous flows. The mixing length $l$ was defined as:

$$
l^{2}=-\left\langle\overline{u^{\prime} w^{\prime}}\right\rangle\left(\frac{\partial\langle\bar{u}\rangle}{\partial z}\right)^{-2}
$$

\section{Results and discussion}

Sections 3.1 and 3.2 address the first objective, Sects. 3.3, 3.4 and 3.5 address the second objective, and Sect. 3.6 addresses the third objective. 


\subsection{Drag distributions and velocity profiles}

In Fig. 5 the vertical distributions of $\left\langle C_{D} a\right\rangle$ as evaluated from Eq. (1) are shown for the R1-R4 cases. In the left panel (Fig. 5a) the vertical distribution of the total plant area per unit volume $a(z)$ evaluated in dry conditions is plotted with the $\left\langle C_{D} a\right\rangle$ distribution of non-reconfigured vegetation (R1; see Sect. 2.3). The central (Fig. 5b) and the right panel (Fig. 5c) show the $\left\langle C_{D} a\right\rangle$ profiles for R1-R2 and R3-R4 cases, respectively.

For R1, where plants exhibited no notable reconfiguration and dynamic motion, the vertical distribution of $\left\langle C_{D} a\right\rangle$ resembled the vertical distribution of $a(z)$ (Fig. 5a). At the top of the bottom grasses, where $\left\langle C_{D} a\right\rangle=\left\langle C_{D} a\right\rangle_{g}$, a local peak due to the drag exerted by grasses (whose frontal area is not included in $a(z)$ ) was present. At $z / h_{v} \approx 0.25$ a minimum in $\left\langle C_{D} a\right\rangle$ was located in a region of reduced plants frontal area above the grasses. For $0.3<z$ $/ h_{v}<0.8$, i.e. the region of maximum $a$ with $a(z)$ presenting only little vertical variation, $\left\langle C_{D} a\right\rangle$ reached a stable high value of $9.0 \pm 1.7 \mathrm{~m}^{-1}$. The vertically averaged drag coefficient $C_{D}$ in this region was $1.5 \pm 0.5$. For $z / h_{v}>0.8$, where $a(z)$ was gradually decreasing to 0 , $\left\langle C_{D} a\right\rangle$ presented an analogous trend, with a rapid decrease at $0.8<z / h_{v}<0.9$. The vertically averaged value of $a(z)$ was $3.7 \mathrm{~m}^{-1}$. The drag-density parameter vertically averaged over the canopy height $\left\langle C_{D} a\right\rangle_{p}$ was $7.5 \mathrm{~m}^{-1}$.

With increasing $U_{b}$, the increasing reconfiguration and the resulting spatial redistribution of the plant material altered the $\left\langle C_{D} a\right\rangle$ distributions. For R2 case, with plants exhibiting low streamlining and bending, the $\left\langle C_{D} a\right\rangle$ distribution resembled that observed for R1 (Fig. 5b), with slightly lower values. For R3, the plants started exhibiting marked reconfiguration $\left(R_{\varepsilon}=20 \%\right)$, the canopy height was $\sim 10 \%$ lower than that of R1 case. The $\left\langle C_{D} a\right\rangle$ distribution (Fig. 5c) presented substantial differences from those of R1 and R2 case. $\left\langle C_{D} a\right\rangle$ peaked at $z / h_{v} \approx 0.6$, with a local value higher than that of the R1-R2 cases, and gradually decreased to 0 at the canopy top. For test case R4, under the highest $U_{b}$, the plants were strongly reconfigured $\left(R_{\varepsilon}=60 \%\right)$ (Fig. 4). The corresponding $\left\langle C_{D} a\right\rangle$ distribution (Fig. $5 \mathrm{c}$ ) was approximately uniform in the region spanning from the top of the bottom grasses to $z$

(a)

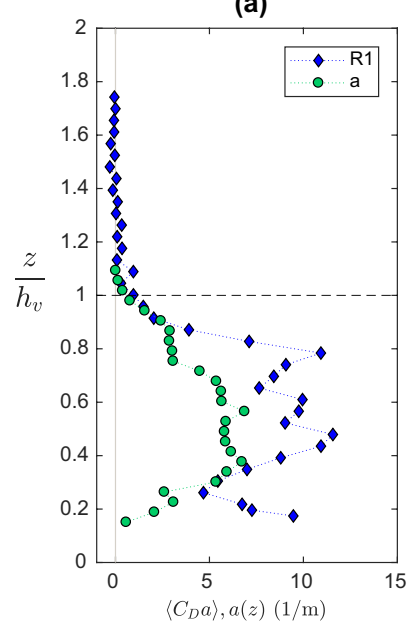

(b)

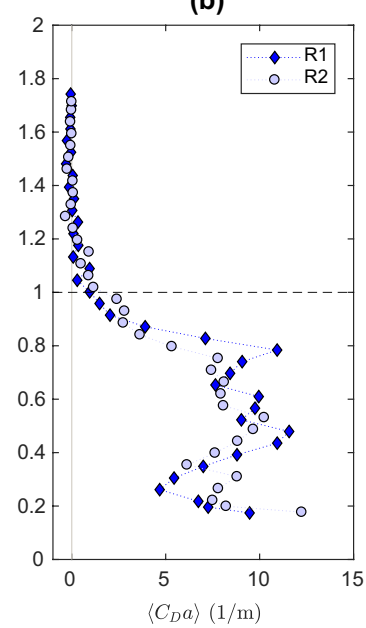

(c)

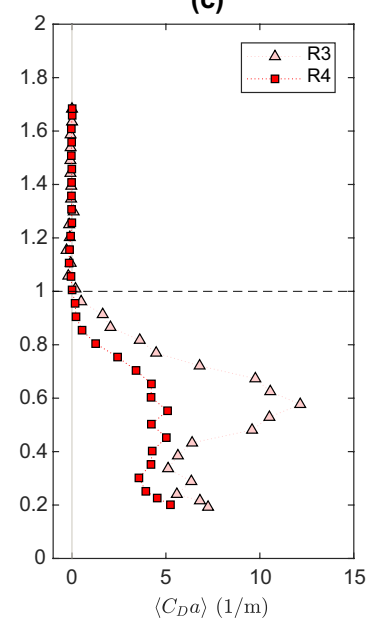

Fig. 5 Vertical distributions of canopy plant area per unit volume and drag-density parameter for R1 case (a). Vertical distribution of drag-density parameter for cases R1-R2 (b) and R3-R4 (c) 
Table 2 Canopy and bottom grasses drag and shear layer characteristic positions. $R_{\varepsilon}$ is the level of vegetation reconfiguration, $\left\langle C_{D} a\right\rangle_{p}$ is the canopy bulk drag-density parameter. $\left\langle C_{D} a\right\rangle_{p} h_{v}$ and $\left\langle C_{D} a\right\rangle_{g} h_{g}$ are the bulk drag-area parameters of the plants and the bottom grasses, respectively. $z_{1}$ and $z_{2}$ are the positions within the velocity profile delimiting the shear layer, $z_{i}$ is the inflection point position, $z_{U_{C}}$ is the position where velocity is equal to $U_{C}$. $\delta$ and $h_{p}$ are the shear layer thickness and the penetration depth, respectively

\begin{tabular}{llllllllllll}
\hline Test case & $R_{\varepsilon}$ & $\begin{array}{c}\left\langle C_{D} a\right\rangle_{p} \\
\left(\mathrm{~m}^{-1}\right)\end{array}$ & $\left\langle C_{D} a\right\rangle_{p} h_{v}$ & $\left\langle C_{D} a\right\rangle_{g} h_{g} \frac{\left\langle C_{D} a\right\rangle_{p} h_{v}}{\left\langle C_{D} a\right\rangle_{g} h_{g}}$ & $\frac{z_{1}}{h_{v}}$ & $\frac{z_{2}}{h_{v}}$ & $\frac{z_{i}}{h_{v}}$ & $\frac{z_{U_{C}}}{h_{v}}$ & $\frac{\delta}{h_{v}}$ & $\frac{h_{p}}{h_{v}}$ \\
\hline $\mathrm{R} 1$ & $0 \%$ & 7.5 & 1.71 & 0.38 & 4.5 & 0.76 & 1.52 & 1.13 & 1.13 & 0.76 & 0.38 \\
$\mathrm{R} 2$ & $5 \%$ & 6.9 & 1.56 & 0.49 & 3.2 & 0.69 & 1.48 & 0.97 & 1.07 & 0.79 & 0.34 \\
$\mathrm{R} 3$ & $20 \%$ & 6.0 & 1.24 & 0.29 & 4.3 & 0.67 & 1.38 & 0.87 & 0.99 & 0.71 & 0.46 \\
$\mathrm{R} 4$ & $60 \%$ & 3.0 & 0.60 & 0.21 & 2.9 & 0.56 & 1.34 & 0.85 & 0.91 & 0.78 & 0.63 \\
\hline
\end{tabular}

(a)

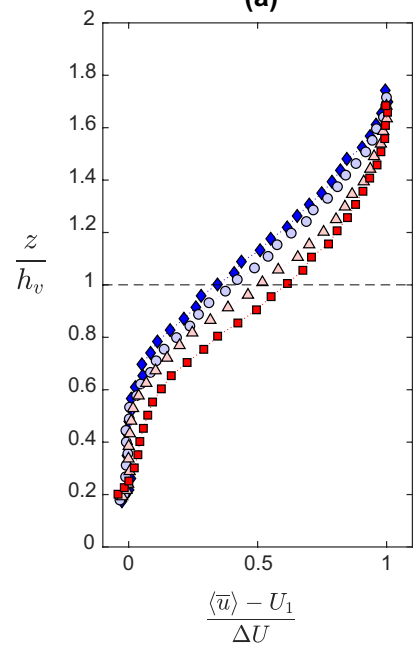

(b)

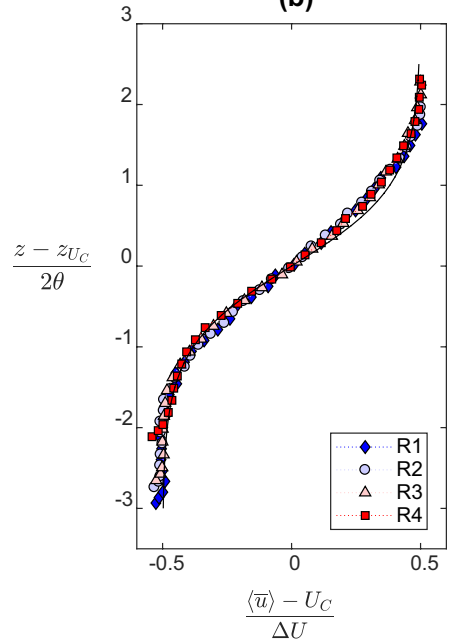

Fig. 6 Normalized vertical velocity profiles for cases R1-R4 (a). Velocity profiles normalized using Eq. (3), with the solid line indicating the hyperbolic tangent profile of Eq. (3) (b)

$/ h_{v} \approx 0.7$, with average $\left\langle C_{D} a\right\rangle$ of $4.2 \pm 0.5 \mathrm{~m}^{-1}$. In the upper part of the canopy, for $0.85<z$ $/ h_{v}<1,\left\langle C_{D} a\right\rangle$ was approximately 0 . The low $\left\langle C_{D} a\right\rangle$ below the canopy top can be explained by the increased bending and streamlining of leaves in this region. Moreover, for R3 and R4 cases, plants exhibited marked dynamic motion (videos, SI). As reported by [31], the drag exerted by blades that deflect under strong sweep events is lower than that exerted by stationary blades. Thus, the organized motion at the canopy top induced an additional local decrease in drag. From R1 to R4, the canopy bulk drag-density parameter $\left\langle C_{D} a\right\rangle_{p}$ decreased from 7.5 to $3.0 \mathrm{~m}^{-1}$ (Table 2).

For all the cases, the drag-density parameter of the bottom grasses $\left\langle C_{D} a\right\rangle_{g}$ assumed relatively high values. The relative importance of the drag exerted by the bottom grasses, described by the ratio $\left\langle C_{D} a\right\rangle_{g} h_{g} /\left\langle C_{D} a\right\rangle_{p} h_{v}$, increased from R1 to R4 with increasing reconfiguration (Table 2). However, for all the tests, the drag exerted by the plants played a key control on the flow, as confirmed by the shape of the velocity profiles. The vertical velocity profiles, with $z$ normalized by $h_{v}$, are shown in Fig. 6, a. Close to the top of the bottom grasses (corresponding to $z / h_{v}=0.17,0.18,0.19,0.20$ for 
R1-R4, respectively), all the velocity profiles resembled a boundary layer. The velocity reached a constant value both in the uppermost region $\left(z / h_{v}>1.6-1.7\right)$, and, for cases R1-R3, deep within the vegetation $\left(\sim 0.25<z / h_{v}<0.6-0.5\right)$. For case R4, the velocity was slowly monotonically increasing within the vegetation. However, the shear layer developing at the vegetation interface was the main feature of all the investigated flows.

The similarity between the velocity distributions of the four cases was evident from the velocity profiles normalized according to Eq. (3) (Fig. 6b). The profiles collapsed on the same curve. For all the tests, the velocity distributions exhibited the typical mixing layer shape commonly observed in the presence of dense submerged vegetation $[32,49]$, for which the vegetative drag is larger compared to the bed drag. Indeed, besides the region close to the grasses top, the velocity profiles were well described by the hyperbolic tangent function of Eq. (3) (Fig. 6b). In the region $0.4<\left(z-z_{U_{C}}\right) / 2 \theta<1.2$, relatively larger differences between the hyperbolic tangent profile and the measured velocities were observed. The shape of the velocity profiles suggests that the drag exerted by the plants was the key dynamic feature governing the flow. With increasing reconfiguration, the relative importance of the drag of the bottom grasses increased (Table 2), altering the shape of the velocity profile within the canopy. Specifically, for R4 case, the shear layer forming between the upper non-vegetated layer and the canopy deeply penetrated the vegetation, interacting with the portion of the boundary layer developing above the grasses (Fig. 6a). As a result, the velocity profile resembled those observed for canopies in transitional regime [49, 89].

The profiles of Fig. 6 are referred to floodplain bushy vegetation with a relative submergence of 2 , for which the shear development is not limited by the water surface. This is a limiting condition for riparian and floodplain areas, where lower submergence ratios are common during overbank flows and floods. Additionally, the results represent a density of vegetation with $\mathrm{LAI} \approx 1$. The behavior of the canopy resembled that of a dense obstruction even under the strongest reconfiguration. The condition was representative of relatively low density, with LAI values commonly ranging at $1-5$ for lowland rivers in continental and boreal climates [22]. Consequently, we expect canopies in transitional regime to be rare in such hydro-environments, under comparable submergence conditions. However, seasonality driven changes in vegetative drag, due for example to shedding of leaves [18], can profoundly alter the canopy drag $[54,75]$. In these conditions, or for higher flow velocities, the bed drag would assume a higher importance, with the transitional and the sparse regime being relevant for describing the flow structure.

The overall shape of the velocity profile remained approximately unvaried with decreasing $\left\langle C_{D} a\right\rangle_{p} h_{v}$ (Fig. 6b). The shear layer shape factor $\delta / \theta$ showed only small variation between the cases, being equal to $4.7 \pm 0.1$. Estimating $\delta$ as in [31] would lead to $\delta / \theta$ $=7.2 \pm 0.4$, thus similar to the values observed for shear layers induced by flexible bladeshaped vegetation $(7.2 \pm 0.2$, [31] ) under analogous submergence conditions. The normalized shear layer thickness $\delta / h_{v}$ remained approximately constant at $0.76 \pm 0.03$ among the cases. It should be noted that $h_{v}$, the height of the deflected vegetation, was variable between the four cases because of bending and streamlining. The relative position of the shear-dominated region of the flow and the canopy interface changed with increasing $U_{b}$ and reconfiguration, as shown in Fig. 6a. The positions $z_{1}$ and $z_{2}$, the position of the velocity profile inflection point $z_{i}$, and $z_{U_{C}}$, progressively shifted downward (Table 2). The share of the shear layer developing within the canopy $\left(\left(h_{v}-z_{1}\right) / \delta\right)$ increased from $\sim 30 \%$ of R1 to $\sim 55 \%$ of R4. Thus, with increasing $U_{b}$ and resulting increase in vegetation reconfiguration, the shear penetration within the canopy $h_{p}$ increased. From R1 to R4, $h_{p} / h_{v}$ varied from 0.38 to 0.63 . 


\subsection{Large-scale vortices and turbulent flow field}

The presence of an inflection point in the velocity profile and the strong shear at the interface triggered the onset of a KH type instability, with the formation of large-scale vortices. In Fig. 7a, the normalized spectra of the longitudinal fluctuating velocity are shown. Each spectrum refers to the plane of maximum turbulent correlation coefficient $\left\langle r_{x z}\right\rangle$, i.e. at $z / h_{v}$ $=1.31,1.11,0.96$ and 0.80 for R1-R4, respectively. Spectral ordinates from the six measurement positions were averaged as to obtain a single spectrum representative of the whole measurement area. The spectra presented a peak in the energy containing range of frequencies approximately corresponding to Strouhal number of 0.032 , the normalized frequency characterizing $\mathrm{KH}$ vortices in canonical plane mixing layers [82]. Spectra exhibited additional peaks at lower Strouhal numbers with increasing $U_{C}$ and the resulting plant reconfiguration and dynamic motion (cases R2-R4).

The dominant frequency of motion of the tracked plant subparts was not always consistent with the dominant frequency of the velocity fluctuations (Table 3). The plant motion was the result of a complex flow-structure interaction problem beyond the scope of this study. However, the advection of vortices induced complex dynamic motions of plants, in turn affecting the flow and driving additional velocity fluctuations at the canopy top. For canopies of aquatic vegetation of blade-shaped tensile vegetation, the dominant frequency of plant motion matched that of the large-scale coherent vortices [31].

The presence of large-scale vortices resulted in strong vertical exchanges of streamwise momentum from the upper non-vegetated layer toward the canopy, as indicated by the vertical distributions of the turbulent correlation coefficient $\left\langle r_{x z}\right\rangle$ (Fig. 7b). The extent of the region where $\left\langle r_{x z}\right\rangle>0.32$ normalized by the canopy height, i.e. $\delta_{v} / h_{v}$, was approximately equal $0.73 \pm 0.03$, roughly equating the shear layer thickness $\delta / h_{v}$. The distributions of $\left\langle r_{x z}\right\rangle$ were asymmetric with a quicker decrease within the canopy. The relative position of the region of

(a)

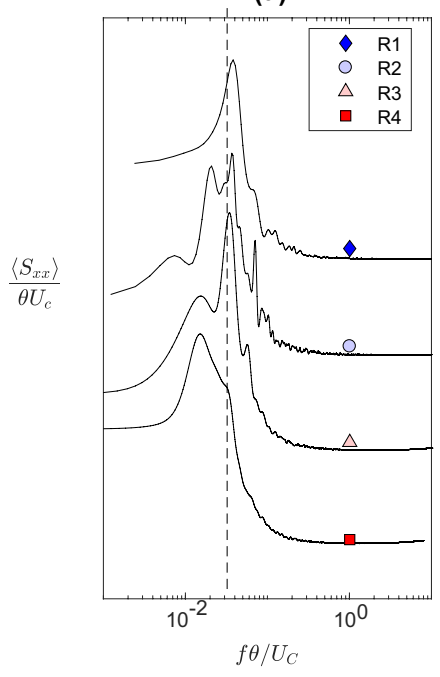

(b)

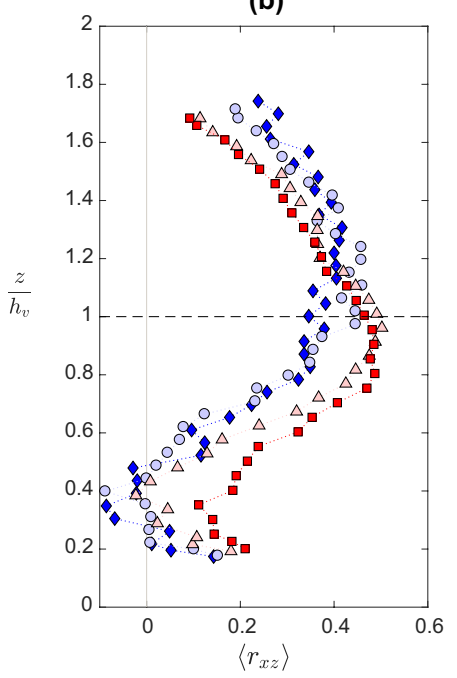

Fig. 7 Normalized spectra (semi-log $x$ ) of the longitudinal fluctuating velocity at location of maximum $\left\langle r_{x z}\right\rangle$ (a). The spectra are shifted vertically for visual clarity. The vertical dashed line corresponds to Strouhal number of 0.032 . Vertical distribution of the spatially averaged turbulent correlation coefficient (b) 


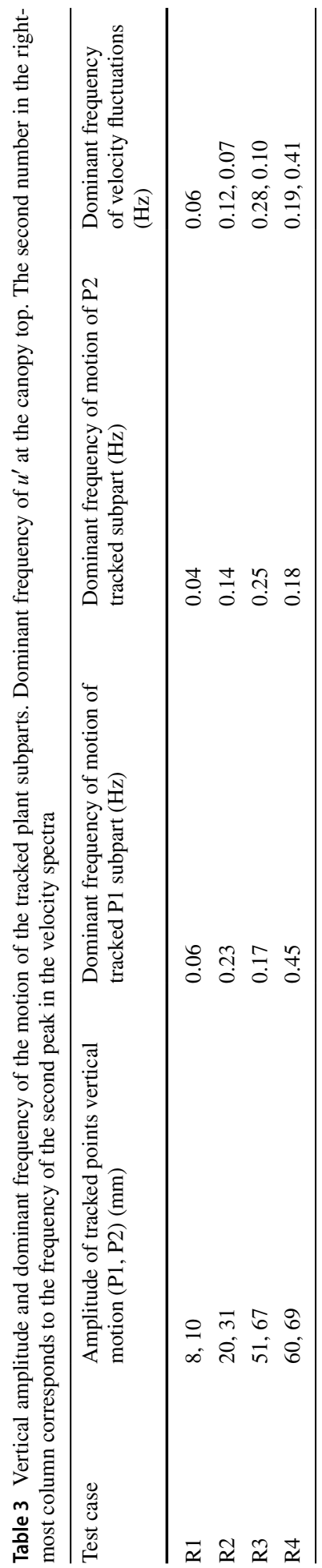


high $\left\langle r_{x z}\right\rangle$ shifted toward the vegetation with increasing $U_{b}$ and plant reconfiguration, consistently with the downward shifting of the inflection point $z_{i}$. Consequently, the penetration of the large-scale vortices within the canopy increased from R1 to R4, with the portion of $\delta_{v}$ located within the vegetation increasing from 20 to $40 \%$. The peak value of $\left\langle r_{x z}\right\rangle$ was approximately equal to 0.44 for R1 and R2 and occurred above the interface. For cases R3 and R4, the maximum $\left\langle r_{x z}\right\rangle$ value was $\sim 0.50$ and was located below the interface. Analogous differences in the magnitude of $\left\langle r_{x z}\right\rangle$ have been linked to the coherent motion of the canopy, with higher values observed for canopies exhibiting monami, both for terrestrial and aquatic canopies $[31,32]$. With increasing $U_{C}$, the kinematics of the vortices was strong enough to cause visible, periodic fluctuations of plants and plant subparts (videos, SI). The amplitude (and the frequency) of the dynamic motion of the plants at the interface increased with increasing $U_{C}$ (Table 3). The coherent motion of the canopy was associated with enhanced vertical transport therein, as indicated by the higher $\left\langle r_{x z}\right\rangle$. Indeed, the structure of a vortex can be more effectively broken by non-waving vegetation, diminishing Reynolds stress penetration [31]. The increasing plant bending at the canopy top and the associated drag reduction, together with the waving motion of the plant material at the interface (R3 and R4 cases), resulted in higher shear penetration, with higher efficiency of vertical momentum exchange in comparison with cases with less (R2) or non-reconfigured vegetation (R1).

Figure 8 shows the vertical distributions of the spatially averaged turbulence intensities of $u^{\prime}, v^{\prime}$ and $w^{\prime}$. The presence of large-scale vortices was reflected in the turbulent velocity field.

For all the cases, the zone of the flow characterized by the presence of large-scale vortices was a region of high turbulence intensity. With increasing penetration of vortices, the region of high turbulence intensity shifted downward from R1 to R4. Across the shear layer, $u^{\prime}$ accounted for approximately $50 \%$ to the turbulent kinetic energy, with contributions of $v^{\prime}$ and $w^{\prime}$ accounting for 25-30 and 20-25\%, respectively. In the region immediately above the bottom grasses, the turbulence intensities associated with $u^{\prime}$ and $v^{\prime}$ were comparable. With increasing reconfiguration, the turbulence intensity within the canopy

(a)

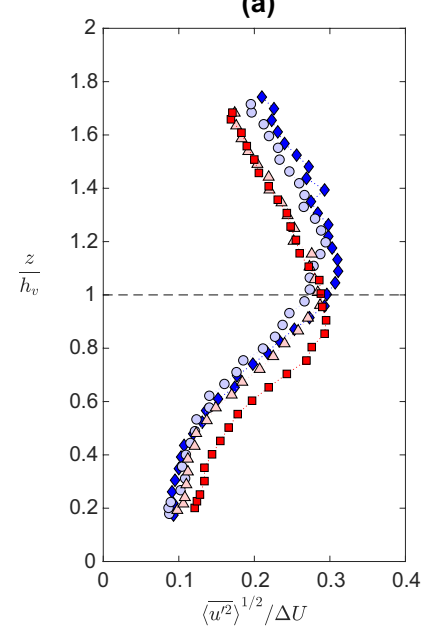

(b)

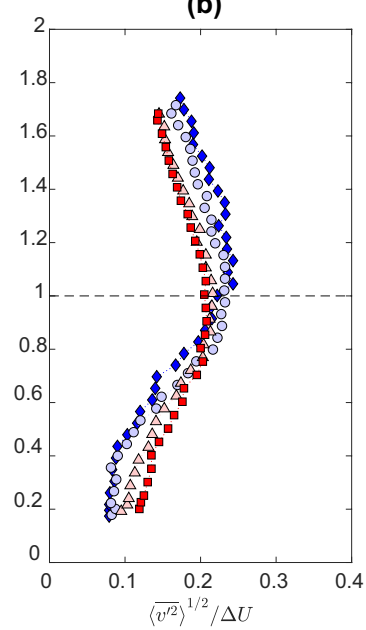

(c)

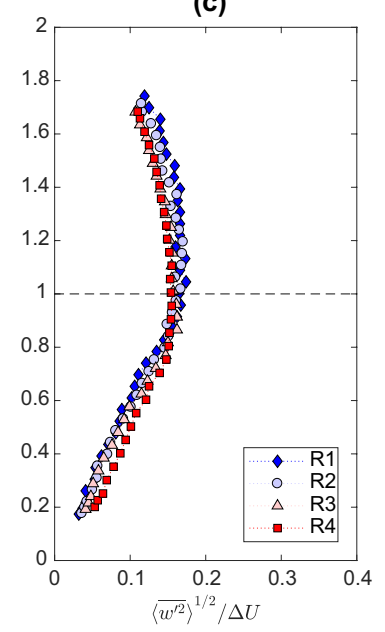

Fig. 8 Vertical distribution of the turbulence intensities of the longitudinal (a), lateral (b) and vertical (c) velocity 
increased, especially that of the lateral fluctuating velocity in the canopy bottom layer. This circumstance has been observed in analogous studies and has been associated with the von Kármán wake generation behind plants [63]. For our configuration this interpretation is realistic for the lower part of the canopy, where less plant material was present and was mainly composed of plant stems. Above the top of the grasses $\left(0.2<z / h_{v}<0.4\right)$ the normalized total turbulent kinetic energy increased with increasing reconfiguration (Figure S6, SI). For R4, the average normalized turbulent kinetic energy in this region was more than doubled in comparison to $\mathrm{R} 1$ case.

\subsection{Flow spatial variability}

The flow over the measurement area presented a marked spatial variability, as indicated by the vertical distributions of $\left\langle\tilde{u}^{2}\right\rangle^{1 / 2},\left\langle\tilde{v}^{2}\right\rangle^{1 / 2}$ and $\left\langle\tilde{w}^{2}\right\rangle^{1 / 2}$ shown in Fig. 9. $\left\langle\tilde{u}^{2}\right\rangle^{1 / 2},\left\langle\tilde{v}^{2}\right\rangle^{1 / 2}$ and $\left\langle\tilde{w}^{2}\right\rangle^{1 / 2}$ represent the form-induced counterpart of the turbulence intensities of Fig. 8 . For all the cases, the standard deviation of $\bar{u}$ over the measurement area, i.e. $\left\langle\tilde{u}^{2}\right\rangle^{1 / 2}$, was higher near the canopy top (Fig. 9a). The magnitude of $\left\langle\tilde{u}^{2}\right\rangle^{1 / 2} / \Delta U$ and the position of maximum variability varied among the cases with different $U_{b}$ and plant reconfiguration. For R1 and R2 cases, the region of high spatial variability of $\bar{u}$ was located at the interface $\left(z / h_{v} \approx 1\right)$. With increasing reconfiguration, i.e. for cases $\mathrm{R} 3$ and $\mathrm{R} 4$, the region of maximum variability shifted downward within the vegetation at $z / h_{v} \approx 0.8$. Above the interface, $\left\langle\tilde{u}^{2}\right\rangle^{1 / 2}$ $/ \Delta U$ gradually decreased to lower values. At the top of the bottom grasses, $\left\langle\tilde{u}^{2}\right\rangle^{1 / 2} / \Delta U$ was approximately equal between the four cases. The portion of the canopy with larger variability of $\bar{u}$ increased under increasing plant reconfiguration (Fig. 9a).

The spatial variability of $\bar{v}$ was relatively low throughout the water column, decreasing toward the water surface (Fig. 9b). The distribution of $\left\langle\tilde{w}^{2}\right\rangle^{1 / 2} / \Delta U$ was affected by reconfiguration and $U_{b}$ (Fig. 9c). For all the cases, $\bar{w}$ presented larger spatial variability within the canopy, while in the non-vegetated layer $\left\langle\tilde{w}^{2}\right\rangle^{1 / 2} / \Delta U \approx 0$. The region of high $\left\langle\tilde{w}^{2}\right\rangle$

(a)

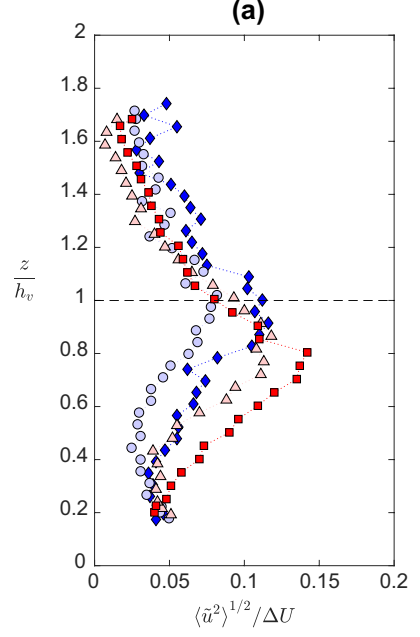

(b)

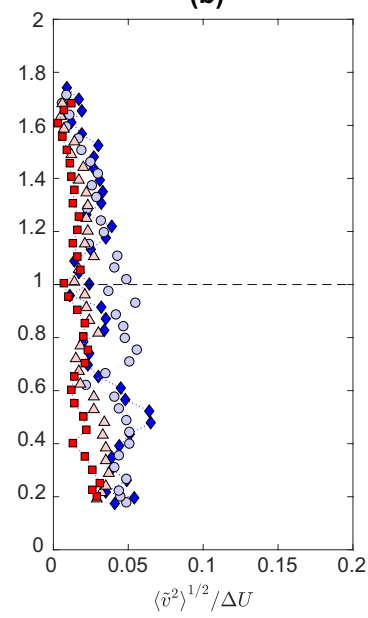

(c)

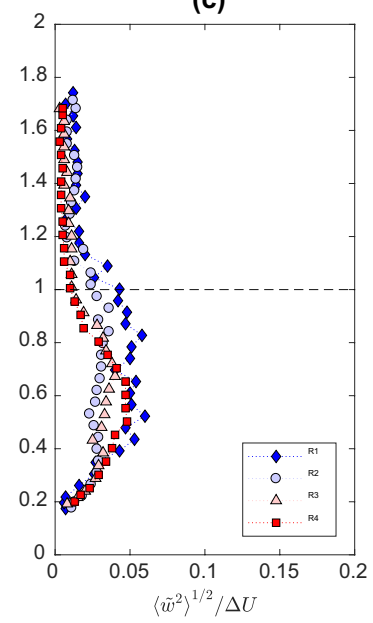

Fig. 9 Vertical distribution of the form-induced intensities of the longitudinal (a), lateral (b) and vertical (c) velocity 
extended from $z / h_{v} \approx 0.4$ to $1-1.1$ for cases with non-reconfigured and slightly reconfigured vegetation (R1 and R2). With increasing $U_{b}$ and reconfiguration (R3 and R4), only the central region of the canopy $\left(0.4<z / h_{v}<0.7\right)$ was characterized by large $\bar{w}$ variability.

The normalized form-induced intensities of $u$ and $w$ decreased from $\mathrm{R} 1$ to $\mathrm{R} 2$, with increasing $U_{b}$. The flow spatial variability for non-reconfigured vegetation was higher than that observed for the R2 case, for which plants started exhibiting streamlining and bending. Further increases in bulk flow velocity, and the consequent increasing reconfiguration (R3 and $\mathrm{R} 4$ cases), resulted in progressively increasing flow spatial variability. The magnitude of $\left\langle\tilde{u}^{2}\right\rangle^{1 / 2} / \Delta U$ and $\left\langle\tilde{w}^{2}\right\rangle^{1 / 2} / \Delta U$ for R1 case was comparable to that of cases R3 and R4. The comparison between Figs. 8 and 9 indicates that the dispersive contribution to the total kinetic energy was relatively low throughout the canopy.

\subsection{Reynolds and dispersive stresses}

Under the DAM, the total fluid stress $\tau$ is partitioned into a turbulent and a dispersive component (Eq. (2)). In Fig. 10 the vertical distributions of the spatially averaged Reynolds stress $-\left\langle\overline{u^{\prime} w^{\prime}}\right\rangle$ (a, left panel), the dispersive stress $-\langle\tilde{u} \tilde{w}\rangle$ (b, central panel), and $\xi$, the fractional contribution of $-\langle\tilde{u} \tilde{w}\rangle$ to the total fluid stress $\tau$ (c, right panel) are shown.

Turbulence was responsible for most of the vertical flux of streamwise momentum. The vertical distributions of $-\left\langle\overline{u^{\prime} w^{\prime}}\right\rangle$ presented a peak near the canopy top. Specifically, the maximum Reynolds stress was located at $z / h_{v}=1.13,1.19,1.01,0.91$ for R1-R4. The position of the peak was above the interface for R1 and R2 cases, and moved toward the canopy with increasing plants reconfiguration and $U_{b}$. Relative to the peak position, the distribution was more symmetric for R1 and R2 cases. For R3 and R4 cases, a marked drop in Reynolds stress occurred within the canopy $\left(z / h_{v}=0.8,0.7\right.$ for R3 and R4, respectively). The shear did not penetrate the canopy because of plant drag. The more symmetric distribution of $-\left\langle\overline{u^{\prime} w^{\prime}}\right\rangle$ for non-reconfigured vegetation can be explained by the distributions

(a)

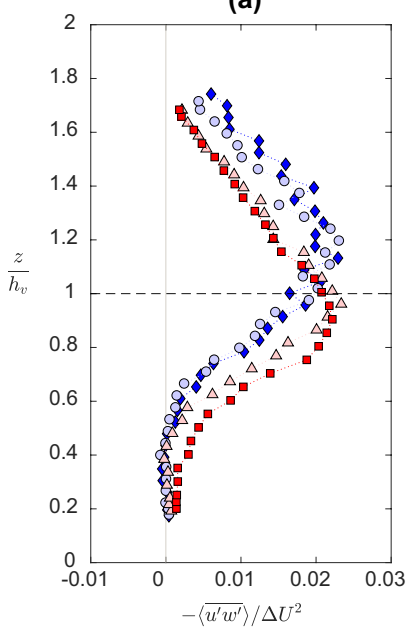

(b)

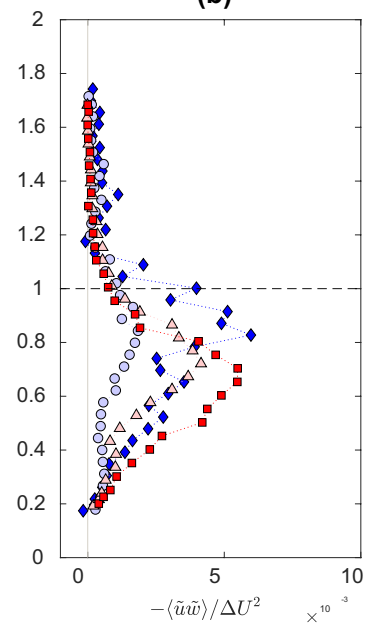

(c)

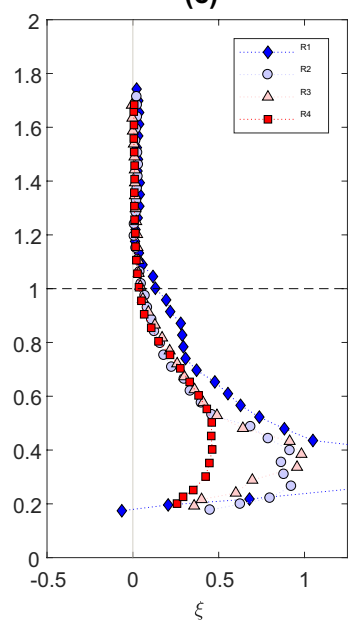

Fig. 10 Vertical distribution of Reynolds (a) and dispersive stresses (b). Vertical distribution of the dispersive to total fluid stress ratio (c). For the R1 profile maximum $\xi<2.15$ 
of $a(z)$ and $\left\langle C_{D} a\right\rangle$ (Fig. 5a and b). For R1, $a(z)$ gradually decreased to 0 at the canopy top toward the upper layer (because of the reduced plant material in this region). This feature resulted in a gradual decrease of vegetative drag toward the upper layer (Fig. 5a and b). Consequently, the Reynolds stresses gradually decreased from the peak moving within the vegetation (Fig. 10a). The increasing $U_{b}$ and the streamlining of plant material at the canopy top induced a marked local reduction in drag. In this region, the drag was further diminished by the organized motion of plant material, resulting in a marked drag discontinuity between the vegetated region and the upper layer (Fig. 5c). As a consequence, the Reynolds stresses exhibited a sharp reduction in the region close to the canopy top (Fig. 10a). In the non-vegetated upper layer, the Reynolds stresses followed the expected linear trend. This linear behavior is a result of the force balance above the canopy, where a constant pressure gradient (first term of Eq. (1)) is balanced by the vertical derivative of the Reynolds stress (second term in Eq. (1)). Reynolds stresses were practically negligible in the region of the canopy not penetrated by the vortex-induced shear.

The flow spatial variability within the canopy and the spatial correlation between the $u$ and $w$ velocity fields contributed to the momentum flux through an additional stress term, the dispersive stresses $-\langle\tilde{u} \tilde{w}\rangle$ (Fig. 10b). For the case with the lowest $U_{b}$ and non-reconfigured vegetation (R1), the magnitude of the dispersive stresses was comparable with that of $\mathrm{R} 4$ case under the highest $U_{b}$ with strongly reconfigured vegetation. The dispersive stresses had their lowest magnitude for R2 case, as observed also for the normal stresses of Fig. 9. For all the cases, $-\langle\tilde{u} \tilde{w}\rangle$ was 0 in the non-vegetated layer and positive throughout the canopy. The dispersive stresses peaked at $z / h_{v} \approx 0.85$ for $\mathrm{R} 1$ and $\mathrm{R} 2$ cases, and at $z / h_{v} \approx 0.70$ for R3 and R4 case. The peak was located at lower height in comparison with the peak in Reynolds stresses. The magnitude of dispersive stresses followed the same trend observed for normal dispersive stresses of Fig. 9. $-\langle\tilde{u} \tilde{w}\rangle / \Delta U^{2}$ increased with increasing $U_{b}$ and plants reconfiguration from R2 to R4. For non-reconfigured vegetation (R1), the magnitude of the normalized dispersive stresses was higher than that of R2 case and comparable to that observed for cases with strongly reconfigured vegetation.

The vertical distributions of $\xi$ (Fig. 10c) indicated that the vertical flux of streamwise momentum was governed by dispersive stresses in the bottom region of the canopy. However, turbulent and dispersive terms were both small in this region (the metric $\xi$ has asymptotic nature). For $z / h_{v}>0.5, \xi$ decreased progressively toward the interface. Slightly higher values were observed for non-reconfigured vegetation close to and below the canopy top (R1). $\xi$ was positive throughout the water column. The magnitude of the dispersive stresses increased from $\mathrm{R} 2$ to $\mathrm{R} 4$ with decreasing $\left\langle C_{D} a\right\rangle_{p}$ from 7 to $3 \mathrm{~m}^{-1}$. The relative importance of dispersive stresses decreased with decreasing canopy bulk drag-density parameter.

For arrays of rigid cylinders, the relative importance of dispersive stresses has been observed to increase with decreasing cylinder density, for $\left\langle C_{D} a\right\rangle_{p}$ values in the range $0.1-4.9 \mathrm{~m}^{-1}$ [62]. This observation suggests that reconfiguration-induced drag reduction is not analogous to an equivalent $\left\langle C_{D} a\right\rangle$ reduction caused by a decrease of the canopy density under the same $U_{b}$. The reconfiguration-induced effects on flow spatial variability cannot be reproduced with simplified vegetation models by controlling the canopy $\left\langle C_{D} a\right\rangle_{p}$. Moreover, velocity measurements in arrays of cylinders revealed the presence of a region of negative $-\langle\tilde{u} \tilde{w}\rangle$ below the canopy top [62]. This circumstance was not observed in our results. For the tested canopy of flexible woody vegetation, vegetation morphology and flexibility played a key role on the flow and its spatial variability that was particularly manifest at the canopy top (Figs. 9 and 10). 


\subsection{Physical interpretation of flow spatial variability and dispersive stresses}

The results of Sects. 3.3 and 3.4 form a basis for a physical interpretation of the spatial variability of flows with reconfiguring vegetation of complex morphology. One way to proceed, as in Moltchanov et al. [58], is to compare at each condition the difference between the local velocity (e.g. $\bar{u}$ ) and the corresponding spatially averaged value (e.g. $\langle\bar{u}\rangle)$ at the same height. This comparison can be effective to understand the flow spatial variability and the normal dispersive stresses of Fig. 9. For the dispersive shear stress of Fig. 10b, representing a correlation term, it is more difficult to develop an intuitive understanding $[58,90]$. The following considerations extend the physical interpretation provided by Moltchanov et al. [58] on the role of canopy density on the dispersive stresses to reconfiguring canopies. The results of Figs. 9 and 10 showed the flow spatial variability and the dispersive stresses to peak both for the R1 case, with low $U_{b}$ and nonreconfigured vegetation, and for R3-R4 cases, with higher $U_{b}$ and strongly reconfigured vegetation. This observation and the increasing magnitude of dispersive stresses under increasing plant streamlining suggested the following physical interpretation of flow spatial variability within floodplain vegetation.

Under low bulk flow velocities (e.g. R1 case), drag forces are too low to induce the streamlining of flexible plant parts and the vortex kinematic is too weak to induce dynamic motions. The presence of woody plants implies the presence of multiple stems, leaves and twigs occupying the flow domain. Downstream of each plant subpart a wake zone is formed, where local velocity is stably lower than the spatially averaged value. In this condition, the canopy drag-density parameter is maximized, resulting in small spatially averaged velocities within the canopy. Consequently, the difference between the local velocity in the wakes and the spatially averaged value is relatively small. Both the number of wakes and the magnitude of the sub-scale velocity difference determine the dispersive stress value. A small increase in $U_{b}$ (e.g. R2 case), sufficiently high to induce the streamlining of the most flexible parts, causes the reduction of the number of the wake zones and their spatial extent. At the same time, because of the small increase in spatially averaged velocity, the difference between local velocity in the wakes and the spatially averaged remains still relatively low. As a result, with plants beginning to reconfigure (R2), the magnitude of dispersive stresses decreases. Further increases in $U_{b}$ (e.g. R3 and R4) induce a progressively stronger streamlining of plants with the onset of marked dynamic motions. Behind a strongly streamlined leaf or a rapidly oscillating flexible part, no wake zone develops, or its extent is much lower in comparison to less or non-reconfigured vegetation. The increase in plant streamlining occurs because of a marked increase in bulk flow velocities. The spatially averaged velocity increases and so the difference with the sub-scale velocity. With increasing plant streamlining, normal dispersive stresses tend to increase because of the increasing velocity difference.

Results of Sects. 3.3-3.5 highlight how the flow spatial variability within flexible canopies of woody plants is the result of a complex, mutual interaction between the structure of the canopy, the flexibility of the plant subparts and their dynamic motion, and the flow. Most importantly, it was found that the relative magnitude of dispersive stresses was larger only in the bottom part of the canopy, i.e. the region not penetrated by the vortices, where both Reynolds and dispersive stresses were small. Consequently, the contribution of dispersive stresses to momentum flux was negligible for the investigated conditions, for which assuming $\tau=-\rho\left\langle\overline{u^{\prime} w^{\prime}}\right\rangle$ in Eq. (1) is then reasonable for hydraulic modelling purposes. 
In addition, our results highlighted that for flows with woody floodplain vegetation, the reliable description of the mean and turbulent flow structure can be performed only when the flow spatial variability is appropriately taken into account. For example, canopy spatial heterogeneity resulted in marked $\bar{u}$ variability at the canopy top and in the region below the interface (Fig. 9) where strong velocity gradients occurred. The flow spatial variability was further profoundly influenced by reconfiguration of plants. Limited spatial sampling or single point velocity measurements cannot address such variability, leading to errors in the estimation of the flow properties (e.g. $u^{*}, U_{C},\langle\bar{u}\rangle(z)$ ). Overall, the investigation of flow spatial variability indicated that the DAM should be considered as a key tool for the experimental and numerical investigation of flows with flexible woody vegetation, as is the case for flows with macro-roughness $[55,57,63,77]$. However, this methodology may not be suited for the analysis of such flow and transport processes for which local and individualscale effects are critical.

\subsection{Comparison with obstructed shear layers}

Environmental obstructed shear layers, including flow over submerged aquatic canopies, coral reefs and granular beds, have been observed to share the four dynamic relations of Eqs. (4-7) linking velocity, length and drag length scales [33]. For flows over waving vegetation, for which the definition of the obstruction height is critical, only the validity of Eqs. (4) and (5) has been verified [33]. As shown in Table 4, the shear layers described in the present study satisfied both Eqs. (4) and (5). It should be noted that, with increasing reconfiguration and dynamic motion at the interface, $\left\langle\overline{w^{\prime 2}}\right\rangle^{1 / 2} / u^{*}$ decreased. This quantity is a measure of the coherence of the large-scale vortices at the interface $[30,75]$. The increasing dynamic motion of the interface resulted in variable drag geometry over time that can reduce the coherence of the large-scale vortices [30].

The scaling of Eq. (6) is related to obstructions with a vertically uniform distribution of the frontal area and, thus, more uniform distributions of $\left\langle C_{D} a\right\rangle$. The obstruction of the present experiments was made of plants with a vertically non-uniform distribution of frontal area, markedly variable in the layer close to the interface. Moreover, the organized motion of plants at the interface caused a decrease in drag in the region penetrated by vortices, roughly corresponding to the region interested by strong dynamic motion. Using $\left\langle C_{D} a\right\rangle_{h_{p}}$, i.e. the $\left\langle C_{D} a\right\rangle$ value averaged over the exchange zone, Eq. (6) provided results more consistent with those observed for other obstructed shear layers (Table 4). The scaling of Eq. (7) was not valid for our experiments and was not expected to be verified. Equation (7) is based on the assumption that the mixing length over the exchange zone scales with the penetration depth $[33,71]$. For our experiments, the mixing length $l$ showed only little

Table 4 Scaling relations for obstructed shear layers

\begin{tabular}{llllll}
\hline Test case & $\frac{\left.\overline{w^{\prime 2}}\right\rangle^{1 / 2}}{u^{*}}$ & $\frac{\left\langle\overline{w^{\prime 2}}\right\rangle}{\left\langle\overline{u^{\prime 2}}\right\rangle}$ & $\left\langle C_{D} a\right\rangle_{p} h_{p}$ & $\left\langle C_{D} a\right\rangle_{h_{p}} h_{p}$ & $\frac{U_{h_{v}}-U_{1}}{u^{*}}$ \\
\hline R1 & 1.08 & 0.57 & 0.66 & 0.48 & 2.27 \\
R2 & 1.06 & 0.61 & 0.54 & 0.36 & 2.78 \\
R3 & 1.05 & 0.57 & 0.57 & 0.42 & 3.39 \\
R4 & 1.04 & 0.53 & 0.38 & 0.34 & 4.13 \\
\hline
\end{tabular}


Fig. 11 Vertical profiles of the mixing length over the sheardominated region of the flow

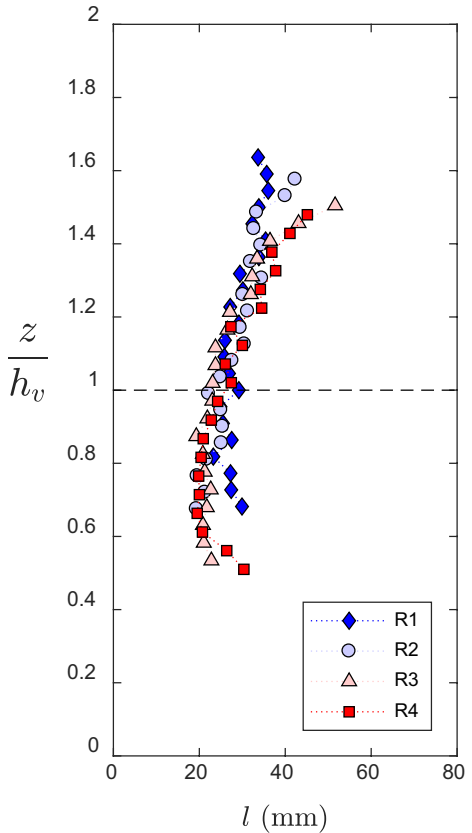

variation over the exchange zone, remaining approximately constant between the four cases (Fig. 11).

This result is consistent with the observations of Ghisalberti and Nepf [30], who proposed the scaling $l \approx \delta / \alpha$ between the mixing length and the shear layer thickness, with $\alpha$ being a constant (equal to 16 for their waving canopy of tensile vegetation). Introducing the $l \approx \delta$ scaling into Eq. (7) yields Eq. (9), valid for the shear layers of this study and those with flexible vegetation under analogous submergence and drag conditions (e.g. [30]):

$$
\frac{U_{h_{v}}-U_{1}}{u^{*}} \frac{\delta}{h_{p}} \approx 5.3 \pm 0.6
$$

The results presented in this section and in Fig. 6. suggest that, once the spatial variability of the flow is properly addressed, shear layers over reconfiguring floodplain vegetation are dynamically similar to other environmental flows over submerged porous obstructions. However, translation of the scalings and results gained on rigid obstructions is difficult to canopies of flexible foliated vegetation. The difficulty to evaluate the canopy bulk dragdensity parameter and the deflected height of vegetation, together with the mismatch between the relative positions of the inflection point, the canopy top, the location of maximum shear stress, and the center of the layer, hinder the use of e.g. Equation 3 for predicting the velocity profile or the use of multi-layer models [91, 92]. For example, the penetration of vortices within the canopy and the consequent shear penetration $h_{p}$, increased with increasing $U_{C}$ and reconfiguration, being larger than predicted by the $h_{p} \sim\left\langle C_{D} a\right\rangle_{p}{ }^{-1}$ scaling of Eq. 7.

The use of Eq. 1 for modelling purposes is straightforward only for non-reconfigured vegetation (i.e. vegetation exhibiting a rigid hydrodynamic behavior). For example, for R1 case, the dispersive part of the total fluid stress can be neglected and a simple mixing 
length model, as the one used by Kubrak et al. [93], is expected to be effective in reproducing the mixing length of Fig. 11. Given the rigid behavior of vegetation of case R1, $a(z)$ in dry conditions is representative of the actual vertical distribution of the canopy frontal area. Assuming a vertically constant drag coefficient, the knowledge of $a(z)$ implies the knowledge of $\left\langle C_{D} a\right\rangle(\mathrm{z})$. Under these hypotheses, Eq. (1) can be numerically solved to obtain $\langle\bar{u}\rangle(\mathrm{z})$. With increasing velocity, the knowledge on $a(z)$ of non-reconfigured vegetation is not sufficient anymore to solve Eq. (1), and a model describing the vegetative drag should be included in the solution [28, 54, 94]. To date, the development and application of such models are limited, with the rigid behavior of vegetation used in experiments and numerical simulations assumed to be suitable for describing flow and transport processes in real settings.

\section{Conclusions}

We investigated the flow over submerged flexible woody plants, simulating conditions often found in floodplains of lowland rivers. Results from previous studies with aquatic flexible vegetation [31] or with rigid cylinders [34, 35] cannot be directly translated to floodplain or riparian hydro-environments $[36,40]$. The originality of this research builds upon the use of model vegetation closely reproducing floodplain conditions in terms of plant structure and flexibility, canopy density and the leaf to stem area ratio $A_{L} / A_{S}$, and presence of a grassy understory. The flow conditions were defined so that vegetation exhibited different degrees of bending and streamlining. The flow measurement strategy was designed to describe the spatially averaged flow using the DAM in a heterogeneous canopy of flexible woody plants, rarely accomplished in prior investigations due to experimental difficulties.

We present a new fluid mechanics interpretation of the role of plant morphology and flexibility in flows over vegetated floodplains. The flows over submerged flexible woody vegetation were dynamically similar to obstructed shear layers found over aquatic vegetation, coral reefs and granular beds. However, our results identified the characteristic morphology of floodplain vegetation with the associated flexibility-induced mechanisms as primary control on the shear layer features. The variable distribution of plant frontal area along with the reconfiguration and dynamic motions were found to govern the vertical distribution of $\left\langle C_{D} a\right\rangle$, regulating the shear penetration within the canopy.

High spatial variability characterized the flows with flexible, foliated woody vegetation. The use of spatially averaged approaches was found a necessity to avoid large errors in deriving the key flow properties and scaling quantities. However, the relative contribution of dispersive stresses to momentum transport was negligible. Dispersive fluxes were relatively high in the canopy bottom region, where both Reynolds and dispersive stresses were small.

Overall, our results indicated that the accurate description of flow over vegetated floodplains is possible only when plant morphology and flexibility are properly described in drag models. We argue that this is a critical step toward the improvement of hydrodynamic modeling of vegetated flows in natural environments.

Supplementary Information The online version contains supplementary material available at https://doi. org/10.1007/s10652-022-09841-w. 
Acknowledgements We gratefully acknowledge the help of laboratory technician Antti Louhio in the flume setup and trainee Roberta D'Angelo for the help in the data collection and pre-processing.

Funding Open Access funding provided by Aalto University. This research was accomplished with the resources from the Aalto University School of Engineering.

\section{Declarations}

Conflict of interest The authors have no conflict of interest to disclose.

Availability of data The data that support the findings of this study are available from the corresponding author upon request.

Open Access This article is licensed under a Creative Commons Attribution 4.0 International License, which permits use, sharing, adaptation, distribution and reproduction in any medium or format, as long as you give appropriate credit to the original author(s) and the source, provide a link to the Creative Commons licence, and indicate if changes were made. The images or other third party material in this article are included in the article's Creative Commons licence, unless indicated otherwise in a credit line to the material. If material is not included in the article's Creative Commons licence and your intended use is not permitted by statutory regulation or exceeds the permitted use, you will need to obtain permission directly from the copyright holder. To view a copy of this licence, visit http://creativecommons.org/licenses/by/4.0/.

\section{References}

1. Mosner E, Schneider S, Lehmann B, Leyer I (2011) Hydrological prerequisites for optimum habitats of riparian Salix communities - identifying suitable reforestation sites. Appl Veg Sci 14:367-377. https:// doi.org/10.1111/j.1654-109X.2011.01121.x

2. Politti E, Bertoldi W, Gurnell A, Henshaw A (2018) Feedbacks between the riparian Salicaceae and hydrogeomorphic processes: a quantitative review. Earth-Sci Rev 176:147-165. https://doi.org/10. 1016/j.earscirev.2017.07.018

3. Li JF, Chen YH, Tfwala S, Chen SC (2021) Effective planting arrangement on floodplains to reduce soil loss in a flood regime: study using physical models. Ecol Eng 167:106258. https://doi.org/10. 1016/j.ecoleng.2021.106258

4. Jongman B (2018) Effective adaptation to rising flood risk. Nat Commun 9:9-11. https://doi.org/10. 1038/s41467-018-04396-1

5. Tamminga A, Eaton B (2018) Linking geomorphic change due to floods to spatial hydraulic habitat dynamics. Ecohydrology 11:1-17. https://doi.org/10.1002/eco.2018

6. Ciszewski D, Grygar TM (2016) A review of flood-related storage and remobilization of heavy metal pollutants in river systems. Water Air Soil Pollut. https://doi.org/10.1007/s11270-016-2934-8

7. Lowrance R (1998) Riparian forest ecosystems as filters for nonpoint-source pollution. Successes, limitations, and frontiers in ecosystem science. Springer, New York, pp 113-141

8. Shields FD, Coulton KG, Nepf HM (2017) Representation of vegetation in two-dimensional hydrodynamic models. J Hydraul Eng 143:02517002. https://doi.org/10.1061/(asce)hy.1943-7900.0001320

9. McBride M, Hession WC, Rizzo DM (2008) Riparian reforestation and channel change: a case study of two small tributaries to Sleepers River, northeastern Vermont, USA. Geomorphology 102:445-459. https://doi.org/10.1016/j.geomorph.2008.05.008

10. Gregory SV, Swanson FJ, Mckee WA, Kenneth W, Swanson J, Cummins KW (1991) An ecosystem perspective of Riparian Zones focus on links between land and water. Bioscience 41:540-551. https:// doi.org/10.2307/1311607

11. Barth NC, Döll P (2016) Assessing the ecosystem service flood protection of a riparian forest by applying a cascade approach. Ecosyst Serv 21:39-52. https://doi.org/10.1016/j.ecoser.2016.07.012

12. European Environment Agency (2020) Floodplains: a natural system to preserve and restore. Publications Office of the European Union

13. Rowiński PM, Västilä K, Aberle J, Järvelä J, Kalinowska MB (2018) How vegetation can aid in coping with river management challenges: a brief review. Ecohydrol Hydrobiol. https://doi.org/10.1016/j. ecohyd.2018.07.003 
14. González del Tánago M, Martínez-Fernández V, Aguiar FC, Bertoldi W, Dufour S, García de Jalón D, Garófano-Gómez V, Mandzukovski D, Rodríguez-González PM (2021) Improving river hydromorphological assessment through better integration of riparian vegetation: scientific evidence and guidelines. J Environ Manage. https://doi.org/10.1016/j.jenvman.2021.112730

15. Lama GFC, Rillo Migliorini Giovannini M, Errico A, Mirzaei S, Padulano R, Chirico GB, Preti F (2021) Hydraulic efficiency of green-blue flood control scenarios for vegetated rivers: $1 \mathrm{D}$ and 2D unsteady simulations. Water 13:2620. https://doi.org/10.3390/w13192620

16. Pugliese F, Caroppi G, Zingraff-Hamed A, Lupp G, Gerundo C (2021) Assessment of NBSs effectiveness for flood risk management: the Isar River case study. J Water Supply Res Technol 00:1-20. https://doi.org/10.2166/aqua.2021.101

17. Nikora VI, Cameron S, Albayrak I, Miler O, Nikora N, Siniscalchi F, Stewart M, O'Hare MT (2012) Flow-biota interactions in aquatic systems : Scales, mechanisms, and challenges. In: Environmental Fluid Mechanics. (pp 217-235) CRC Press

18. Caroppi G, Västilä K, Järvelä J, Lee C, Ji U, Kim HS, Kim S (2022) Flow and wake characteristics associated with riparian vegetation patches: results from field-scale experiments. Hydrol Process. https://doi.org/10.1002/hyp.14506

19. Aberle J, Järvelä J (2013) Flow resistance of emergent rigid and flexible floodplain vegetation. J Hydraul Res 51:33-45. https://doi.org/10.1080/00221686.2012.754795

20. Rowiński PM, Okruszko T, Radecki-Pawlik A (2021) Environmental hydraulics research for river health: recent advances and challenges. Ecohydrol Hydrobiol. https://doi.org/10.1016/j.ecohyd. 2021.12.003

21. Hession WC, Curran JC (2013) The Impacts of Vegetation on Roughness in Fluvial Systems. In: Butler DR, Hupp CR (eds) Treatise on Geomorphology. (pp 75-93) Elsevier Ltd

22. Box W, Järvelä J, Västilä K (2021) Flow resistance of floodplain vegetation mixtures for modelling river flows. J Hydrol 601:126593. https://doi.org/10.1016/j.jhydrol.2021.126593

23. Cotton JA, Wharton G, Bass JAB, Heppell CM, Wotton RS (2006) The effects of seasonal changes to in-stream vegetation cover on patterns of flow and accumulation of sediment. Geomorphology 77:320-334. https://doi.org/10.1016/j.geomorph.2006.01.010

24. Boothroyd RJ, Nones M, Guerrero M (2021) Deriving planform morphology and vegetation coverage from remote sensing to support river management applications. Front Environ Sci 9:1-18. https://doi.org/10.3389/fenvs.2021.657354

25. Tal M, Paola C (2007) Dynamic single-thread channels maintained by the interaction of flow and vegetation. Geology 35:347-350. https://doi.org/10.1130/G23260A.1

26. Li F, Shan Y, Huang S, Liu C, Liu X (2021) Flow depth, velocity, and sediment motions in a straight widened channel with vegetated floodplains. Environ Fluid Mech 21:483-501. https://doi. org/10.1007/s10652-021-09783-9

27. Dittrich A, Aberle J, Schoneboom T (2012) Drag forces and flow resistance of flexible riparian vegetation. In: Environmental Fluid Mechanics: Memorial Volume in Honour of Prof. Gerhard H. Jirka

28. Västilä K, Järvelä J (2018) Characterizing natural riparian vegetation for modeling of flow and suspended sediment transport. J Soils Sedim. https://doi.org/10.1007/s11368-017-1848-4

29. Nepf HM, Vivoni ER (2000) Flow structure in depth-Iimited, vegetated flow. J Geophys Res 105:28547-28557. https://doi.org/10.1029/2000JC900145

30. Ghisalberti M, Nepf HM (2006) The structure of the shear layer in flows over rigid and flexible canopies. Environ Fluid Mech 6:277-301. https://doi.org/10.1007/s10652-006-0002-4

31. Ghisalberti M, Nepf HM (2002) Mixing layers and coherent structures in vegetated aquatic flows. J Geophys Res 107:1-11. https://doi.org/10.1029/2001JC000871

32. Raupach MR, Finnigan JJ, Brunet Y (1996) Coherent eddies and turbulence in vegetation canopies: the mixing-layer analogy. Boundary-Layer Meteorol 78:351-382. https://doi.org/10.1007/BF001 20941

33. Ghisalberti M (2009) Obstructed shear flows: similarities across systems and scales. J Fluid Mech 641:51-61. https://doi.org/10.1017/S0022112009992175

34. Nezu I, Sanjou M (2008) Turburence structure and coherent motion in vegetated canopy openchannel flows. J Hydro-Environ Res 2:62-90. https://doi.org/10.1016/j.jher.2008.05.003

35. Poggi D, Porporato A, Ridolfi L, Albertson JD, Katul GG (2004) The effect of vegetation density on canopy sub-layer turbulence. Boundary-Layer Meteorol 111:565-587. https://doi.org/10. 1023/B:BOUN.0000016576.05621.73

36. Caroppi G, Västilä K, Gualtieri P, Järvelä J, Giugni M, Rowiński PM (2021) Comparison of flexible and rigid vegetation induced shear layers in partly vegetated channels. Water Resour Res. https:// doi.org/10.1029/2020wr028243 
37. Ghisalberti M, Nepf HM (2009) Shallow flows over a permeable medium: the hydrodynamics of submerged aquatic canopies. Transp Porous Media 78:385-402. https://doi.org/10.1007/ s11242-009-9434-X

38. Nepf HM, Ghisalberti M, White BL, Murphy E (2007) Retention time and dispersion associated with submerged aquatic canopies. Water Resour Res 43:1-10. https://doi.org/10.1029/2006W R005362

39. Dunn C, Lopez F, García MH (1996) Mean flow and turbulence in a laboratory channel with simulated vegatation (HES 51)

40. Tinoco RO, San Juan JE, Mullarney JC (2020) Simplification bias: lessons from laboratory and field experiments on flow through aquatic vegetation. Earth Surf Process Landf 45:121. https://doi. org/10.1002/esp.4743

41. Łoboda AM, Karpiński M, Bialik RJ (2018) On the relationship between aquatic plant stem characteristics and drag force: is a modeling application possible? Water (Switzerland). https://doi.org/10. 3390/w10050540

42. Łoboda AM, Bialik RJ, Karpiński M, Przyborowski Ł (2019) Two simultaneously occurring Potamogeton species: similarities and differences in seasonal changes of biomechanical properties. Polish J Environ Stud 28:237-253. https://doi.org/10.15244/pjoes/85202

43. Przyborowski Ł, Łoboda AM, Bialik RJ, Västilä K (2019) Flow field downstream of individual aquatic plants-experiments in a natural river with Potamogeton crispus L. and Myriophyllum spicatum L. Hydrol Process 33:1324-1337. https://doi.org/10.1002/hyp.13403

44. Abdolahpour M, Ghisalberti M, Mcmahon K, Lavery PS (2018) The impact of flexibility on flow, turbulence, and vertical mixing in coastal canopies. Limnol Oceanogr. https://doi.org/10.1002/lno.11008

45. Termini D (2015) Flexible vegetation behaviour and effects on flow conveyance: experimental observations. Int J River Basin Manag 13:401-411. https://doi.org/10.1080/15715124.2015.1012519

46. Weissteiner C, Jalonen J, Järvelä J, Rauch HP (2015) Spatial-structural properties of woody riparian vegetation with a view to reconfiguration under hydrodynamic loading. Ecol Eng 85:85-94. https://doi. org/10.1016/j.ecoleng.2015.09.053

47. Harder DL, Speck O, Hurd CL, Speck T (2004) Reconfiguration as a prerequisite for survival in highly unstable flow-dominated habitats. J Plant Growth Regul. https://doi.org/10.1007/s00344-004-0043-1

48. Vogel S (1989) Drag and reconfiguration of broad leaves in high winds. J Exp Bot 40:941-948. https:// doi.org/10.1093/jxb/40.8.941

49. Nepf HM (2012) Flow and transport in regions with aquatic vegetation. Annu Rev Fluid Mech 44:123142. https://doi.org/10.1146/annurev-fluid-120710-101048

50. Ackerman JD, Okubo A (1993) Reduced mixing in a marine macrophyte canopy. Funct Ecol 7:305309. https://doi.org/10.2307/2390209

51. O’Connor J, Revell A (2019) Dynamic interactions of multiple wall-mounted flexible flaps. J Fluid Mech 870:189-216. https://doi.org/10.1017/jfm.2019.266

52. Okamoto TA, Nezu I (2009) Turbulence structure and "Monami" phenomena in flexible vegetated open-channel flows. J Hydraul Res 47:798-810. https://doi.org/10.3826/jhr.2009.3536

53. Boothroyd RJ, Hardy RJ, Warburton J, Marjoribanks TI (2017) Modeling complex flow structures and drag around a submerged plant of varied posture. Water Resour Res. https://doi.org/10.1002/2015W R017200.A

54. Västilä K, Järvelä J (2014) Modeling the flow resistance of woody vegetation using physically based properties of the foliage and stem. Water Resour Res 50:229-245. https://doi.org/10.1002/2013W R013819

55. Aberle J, Koll K, Dittrich A (2008) Form induced stresses over rough gravel-beds. Acta Geophys 56:584-600. https://doi.org/10.2478/s11600-008-0018-x

56. Coscarella F, Penna N, Ferrante AP, Gualtieri P, Gaudio R (2021) Turbulent flow through random vegetation on a rough bed. Water. https://doi.org/10.3390/w13182564

57. Nikora VI, McLean S, Coleman S, Pokrajac D, McEwan I, Campbell L, Aberle J, Clunie D, Koll K (2007) Double-averaging concept for rough-bed open-channel and overland flows: theoretical background. J Hydraul Eng 133:884-895. https://doi.org/10.1061/(ASCE)0733-9429(2007)133:8(884)

58. Moltchanov S, Bohbot-Raviv Y, Duman T, Shavit U (2015) Canopy edge flow: a momentum balance analysis Sharon. Water Resour Res 51:2081-2095. https://doi.org/10.1002/2014WR015397

59. Bohrer G, Katul GG, Walko RL, Avissar R (2009) Exploring the effects of microscale structural heterogeneity of forest canopies using large-eddy simulations. Boundary-Layer Meteorol 132:351-382. https://doi.org/10.1007/s10546-009-9404-4

60. Duman T, Bohbot-Raviv Y, Moltchanov S, Shavit U (2021) Error estimates of double-averaged flow statistics due to sub-sampling in an irregular canopy model. Boundary-Layer Meteorol 179:403-422. https://doi.org/10.1007/s10546-020-00601-1 
61. Tinoco RO, San Juan JE, Mullarney JC (2020) Simplification bias: lessons from laboratory and field experiments on flow through aquatic vegetation. Earth Surf Process Landf 45:121-143. https://doi.org/ 10.1002/esp.4743

62. Poggi D, Katul GG, Albertson JD (2004) A note on the contribution of dispersive fluxes to momentum transfer within canopies. Boundary-Layer Meteorol 111:615-621. https://doi.org/10.1023/B:BOUN. 0000016563.76874 .47

63. Righetti M (2008) Flow analysis in a channel with flexible vegetation using double-averaging method. Acta Geophys 56:801-823. https://doi.org/10.2478/s11600-008-0032-z

64. Berends KD, Ji U, Penning WE, Warmink JJ, Kang J, Hulscher SJMH (2020) Stream-scale flow experiment reveals large influence of understory growth on vegetation roughness. Adv Water Resour. https:// doi.org/10.1016/j.advwatres.2020.103675

65. Penna N, Coscarella F, D'Ippolito A, Gaudio R (2020) Bed roughness effects on the turbulence characteristics of flows through emergent rigid vegetation. Water (Switzerland). https://doi.org/10.3390/ W12092401

66. Nakai T, Sumida A, Matsumoto K, Daikoku K, Iida S, Park H, Miyahara M, Kodama Y, Kononov AV, Maximov TC, Yabuki H, Hara T, Ohta T (2008) Aerodynamic scaling for estimating the mean height of dense canopies. Boundary-Layer Meteorol 128:423-443. https://doi.org/10.1007/ s10546-008-9299-5

67. Kouwen N, Unny TE (1973) Flexible roughness in open channels. J Hydraul Div 99:713-728. https://doi.org/10.1061/JYCEAJ.0003643

68. Järvelä J (2005) Effect of submerged flexible vegetation on flow structure and resistance. J Hydrol 307:233-241. https://doi.org/10.1016/j.jhydrol.2004.10.013

69. Heady HF (1957) The measurement and value of plant height in the study of herbaceous vegetation. Ecology 38:313-320. https://doi.org/10.2307/1931691

70. Finnigan JJ (2000) Turbulence in plant canopies. Annu Rev Fluid Mech. https://doi.org/10.1146/ annurev.fluid.32.1.519

71. Ghisalberti M, Nepf HM (2004) The limited growth of vegetated shear layers. Water Resour Res 40:1-12. https://doi.org/10.1029/2003WR002776

72. Jesson MA, Bridgeman J, Sterling M (2015) Novel software developments for the automated postprocessing of high volumes of velocity time-series. Adv Eng Softw 89:36-42. https://doi.org/10. 1016/j.advengsoft.2015.06.007

73. Parsheh M, Sotiropoulos F, Porté-Agel F (2010) Estimation of power spectra of acoustic-doppler velocimetry data contaminated with intermittent spikes. J Hydraul Eng 136:368-378. https://doi. org/10.1061/(ASCE)HY.1943-7900.0000202

74. Caroppi G, Gualtieri P, Fontana N, Giugni M (2020) Effects of vegetation density on shear layer in partly vegetated channels. J Hydro-Environ Res 30:82-90. https://doi.org/10.1016/j.jher.2020.01. 008

75. Caroppi G, Västilä K, Järvelä J, Rowiński PM, Giugni M (2019) Turbulence at water-vegetation interface in open channel flow: experiments with natural-like plants. Adv Water Resour 127:180191. https://doi.org/10.1016/j.advwatres.2019.03.013

76. Raupach MR, Shaw RH (1982) Averaging procedures for flow within vegetation canopies. Boundary-Layer Meteorol 22:79-90. https://doi.org/10.1007/BF00128057

77. Nikora VI, Rowiński PM (2008) Rough-bed flows in geophysical, environmental, and engineering systems: double-averaging approach and its applications. Acta Geophys 56:529-533. https://doi. org/10.2478/s11600-008-0037-7

78. Harman IN, Böhm M, Finnigan JJ, Hughes D (2016) Spatial variability of the flow and turbulence within a model canopy. Boundary-Layer Meteorol 160:375-396. https://doi.org/10.1007/ s10546-016-0150-0

79. Bai K, Katz J, Meneveau C (2015) Turbulent flow structure inside a canopy with complex multi-scale elements. Boundary-Layer Meteorol 155:435-457. https://doi.org/10.1007/ s10546-015-0011-2

80. King AT, Tinoco RO, Cowen EA (2012) A k- $\varepsilon$ turbulence model based on the scales of vertical shear and stem wakes valid for emergent and submerged vegetated flows. J Fluid Mech 701:1-39. https://doi.org/10.1017/jfm.2012.113

81. Pope SB (2000) Turbulent flows. Cambridge University Press

82. Rogers MM, Moser RD (1994) Direct simulation of a self-similar turbulent mixing layer. Phys Fluids 6:903-923. https://doi.org/10.1063/1.868325

83. Huai W, Zhang J, Katul GG, Cheng Y, Tang X, Wang W (2019) The structure of turbulent flow through submerged flexible vegetation. J Hydrodyn. https://doi.org/10.1007/s42241-019-0023-3 
84. Nikora VI, Goring DG, McEwan I, Griffiths G (2001) Spatially averaged open-channel flow over rough bed. J Hydraul Eng 127:123-133

85. Marjoribanks TI, Hardy RJ, Lane SN, Parsons DR (2017) Does the canopy mixing layer model apply to highly flexible aquatic vegetation? Insights from numerical modelling. Environ Fluid Mech 17:277-301. https://doi.org/10.1007/s10652-016-9482-z

86. Solomon MO (1991) PSD Computations Using Welch's Method

87. Kaimal JCC, Finnigan JJ (1994) Atmospheric boundary layer flows: their structure and measurement. Oxford University Press, New York

88. Caroppi G, Gualtieri P, Fontana N, Giugni M (2018) Vegetated channel flows: turbulence anisotropy at flow-rigid canopy interface. Geosci. https://doi.org/10.3390/geosciences8070259

89. Monti A, Omidyeganeh M, Eckhardt B, Pinelli A (2020) On the genesis of different regimes in canopy flows: a numerical investigation. J Fluid Mech. https://doi.org/10.1017/jfm.2020.155

90. Moltchanov S, Shavit U (2013) A phenomenological closure model of the normal dispersive stresses. Water Resour Res 49:8222-8233. https://doi.org/10.1002/2013WR014488

91. Nikora N, Nikora VI, O'Donoghue T (2013) Velocity profiles in vegetated open-channel flows: combined effects of multiple mechanisms. J Hydraul Eng 139:1021-1032. https://doi.org/10.1061/ (ASCE)HY.1943-7900.0000779

92. Rubol S, Ling B, Battiato I (2018) Universal scaling-law for flow resistance over canopies with complex morphology. Sci Rep 8:4430. https://doi.org/10.1038/s41598-018-22346-1

93. Kubrak E, Kubrak J, Rowiński PM (2008) Vertical velocity distributions through and above submerged, flexible vegetation. Hydrol Sci Journal-Journal Des Sci Hydrol 53:905-920. https://doi.org/ 10.1623/hysj.53.4.905

94. Whittaker P, Wilson CAME, Aberle J (2015) An improved Cauchy number approach for predicting the drag and reconfiguration of flexible vegetation. Adv Water Resour 83:28-35. https://doi.org/10.1016/j. advwatres.2015.05.005

Publisher's Note Springer Nature remains neutral with regard to jurisdictional claims in published maps and institutional affiliations.

\section{Authors and Affiliations}

\section{Gerardo Caroppi $^{1}\left[\mathbb{D}\right.$. Juha Järvelä ${ }^{1}$}

Gerardo Caroppi

gerardo.caroppi@aalto.fi

1 Department of Built Environment, Aalto University School of Engineering, Espoo, Finland 